\title{
Lithospheric dynamics in the vicinity of the Tengchong volcanic field (southeastern margin of Tibet): an investigation using $P$ receiver functions
}

\author{
Hengchu Peng, ${ }^{1}$ José Badal, ${ }^{2}$ Jiafu Hu ${ }^{\oplus},{ }^{1}$ Haiyan Yang ${ }^{1}$ and Benyu Liu ${ }^{1}$ \\ ${ }^{1}$ Department of Geophysics, Yunnan University, 2 North Green Lake Rd., Kunming, Yunnan 650091, P.R. China. E-mail: jfhu96@163.com \\ ${ }^{2}$ Physics of the Earth, Sciences B, University of Zaragoza, Pedro Cerbuna 12, 50009 Zaragoza, Spain
}

Accepted 2020 October 22. Received 2020 October 13; in original form 2020 May 1

\begin{abstract}
SUMMAR Y
Tengchong volcanic field (TVF) in the northern Indochina block lies in a critical area for understanding complex regional dynamics associated with continent-continent convergence between the Indian and Eurasian plates, including northeastward compression generated by subduction of the Indian Plate beneath the Burma Arc, and southeastward lateral extrusion of the crust from below central Tibet. We gathered 3408 pairs of $P$ receiver functions with different frequencies and calculated the splitting parameters of the Moho-converted Pms phase. An anisotropic $H-\kappa$ stacking algorithm was used to determine crustal thickness and $\mathrm{Vp} / \mathrm{Vs}$ ratios. We also inverted for the detailed $S$-velocity structure of the crust and upper mantle using a twostep inversion technique. Finally, we mapped the topography of the lithosphere-asthenosphere boundary. Results show fast-wave polarization directions with a dominant NE-SW orientation and delay times varying between 0.19 and $1.22 \mathrm{~s}$, with a mean of $0.48 \pm 0.07 \mathrm{~s}$. The crustal $\mathrm{Vp} / \mathrm{Vs}$ ratio varies from 1.68 to 1.90 and shows a maximum value below the central part of the TVF, where there is relatively thin crust $(\sim 35-39 \mathrm{~km})$ and a pronounced low-velocity anomaly in the middle-lower crust. The depth of the lithosphere-asthenosphere boundary ranges from 53 to $85 \mathrm{~km}$ : it is relatively deep $(\sim 70-85 \mathrm{~km})$ in the vicinity of the TVF and relatively shallow in the south of the study area. In the absence of low shear wave velocity in the upper mantle below the TVF, we propose that the low-velocity anomaly in the lower crust beneath the TVF derives from the upper mantle below the neighbouring Baoshan block.
\end{abstract}

Key words: Crustal imaging; Seismic anisotropy; Dynamics of lithosphere and mantle; Kinematics of crustal and mantle deformation; Magma migration and fragmentation.

\section{INTRODUCTION}

Convergence between India and Eurasia since $\sim 45$ Ma has led to southeastward extrusion of the lithosphere from central Tibet towards South China and Indochina (Royden et al. 2008). GPS measurements (Zhang et al. 2004) indicate that the crust is undergoing clockwise rotation around the East Himalayan Syntax (EHS) along the southeastern margin of Tibet. Tengchong volcano is located in the northern Indochina block, in southeastern margin of Tibet and near the border between China and Burma (Fig. 1a). The last eruption of the volcano occurred in 1609 (Jiang 1998), but numerous surface geological features, such as active hot springs, indicate that the volcano still has potential for future eruptions (Wang et al. 2007). To the west of the Tengchong volcanic field (TVF), seismicity beneath the Indo-Burmese confluence reveals a Wadati-Benioff zone that dips eastwards (Ni et al. 1989), which implies the presence of subducted Indian lithosphere. The TVF $\left(24^{\circ} 40^{\prime}-25^{\circ} 30^{\prime} \mathrm{N}\right.$, $\left.98^{\circ} 15^{\prime}-98^{\circ} 45^{\prime} \mathrm{E}\right)$ is regarded as a transition zone that is subject to northeastward compression generated by subduction of the Indian Plate below the Himalayas, and clockwise rotation around the EHS (Wang \& Burchfiel 1997; Zhang et al. 2004).

In the last decades, various studies of the TVF have contributed to an understanding of its formation (e.g. Wang \& Huangfu 2004; Wang et al. 2007; Lei et al. 2009). However, because of the sparse distribution of seismic stations and/or the limitations of analytical methods, as well as insufficient coverage from seismic rays, the origin of the TVF remains a subject of debate. Tomographic images based on local and teleseismic data have revealed that an extensive low-velocity volume east of the TVF extends from the subsurface to 200-300 km depth (Li et al. 2008; Lei et al. 2009; Huang et al. 2015). Some studies have argued that dehydration of the deeply subducted Indian slab induces mantle upwelling from the mantle transition zone (MTZ; Lei et al. 2009). Other models have proposed that tearing of the subducted Indian lithospheric slab, occurring at depths of $<400 \mathrm{~km}$, may have triggered an upwelling 

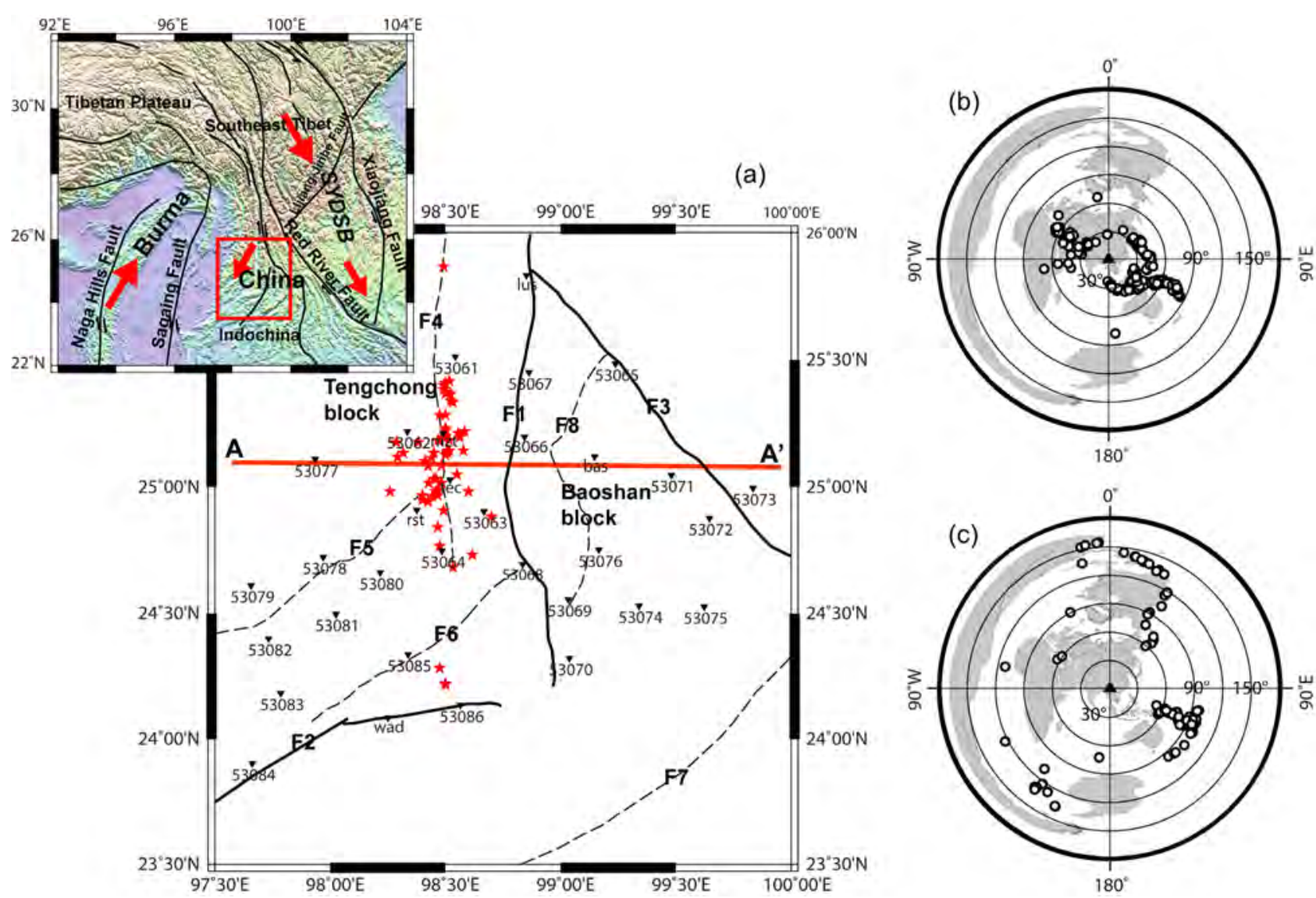

Figure 1. Tectonic setting and locations of the seismic events used in this study shown on a worldwide map. (a) Locations of Tengchong volcanic cones (red stars), major faults (solid lines) and regional faults (dashed lines) in the northern Indochina block. Inverted triangles indicate the locations of permanent seismic stations (three-letter codes) or temporary stations (five-digit numbers). Symbols: F1, Nujiang Fault; F2, Wanding Fault; F3, Lancangjiang Fault; F4, Tengchong Rift; F5, Yinjiang Fault; F6, Longling-Ruili Fault; F7, Nantinghe Fault; F8, Baoshan-Shidian Fault. The red line labelled A-A' marks the location of the vertical seismic velocity cross-section presented in Fig. 10. The inset in the upper-left corner shows the main tectonic blocks separated by major faults (solid lines) and includes a red-bordered rectangle that delimits the study area. The abbreviation SYDSB means Sichuan-Yunnan diamond-shaped block. Red arrows indicate GPS vectors (not drawn to scale) representing the stress regime at the surface. (b) Earthquakes at epicentral distances of $30^{\circ}-95^{\circ}$ on a worldwide map (small circles) used to isolate PRFs. (c) Earthquakes at epicentral distances of $60^{\circ}-165^{\circ}$ on a worldwide map (small circles) used to isolate SRFs.

stream of hot material that feeds the TVF (Zhang et al. 2017). However, geochronological studies suggest that possible tearing of the subducted Indian Plate during the Eocene is inconsistent with Cenozoic eruptions in the TVF (Xu et al. 2008). Receiver-function analysis has revealed a significantly depressed discontinuity at $410 \mathrm{~km}$ depth and a thickened MTZ below the Tengchong area (Zhang et al. 2017; Xu et al. 2018). This may indicate the presence of fluids in the MTZ (Helffrich 2000), and supports the hypothesis that the TVF originates in the MTZ or from the $410 \mathrm{~km}$ discontinuity (Xu et al. 2018).

In addition to the uncertainty regarding the deep origin of the TVF, low resistivity (Ye et al. 2018), high heat flow (Hu et al. 2000) and the presence of numerous hot springs with temperatures above $90^{\circ} \mathrm{C}$ (Jiang 1998), suggest the existence of magma chambers and hot materials within the crust. However, surficial geological features cannot provide direct constraints on deformation in the middle to lower crust. On the basis of deep seismic reflection studies performed in the Tengchong area, Wang \& Huangfu (2004) reported a low-velocity anomaly in the upper crust that they interpreted as partial melt. However, they were unable to determine where the magmas originated, although they speculated that the volcanoes in Tengchong could be classified as plate-boundary volcanoes. Joint inversion of receiver functions and Rayleigh-wave dispersion (Bao et al. 2015; Li et al. 2016) have revealed a small low-velocity anomaly in the upper crust above $20 \mathrm{~km}$ depth, whereas the lower crust and uppermost mantle are characterized by relatively high velocities in the Tengchong area. Most of these previous studies focused on lower-crustal flow originating below central Tibet, rather than the origins of the TVF.

Petrological studies have suggested that there may be three magma chambers underlying the TVF (Zhao et al. 2006), whereas $P$ receiver functions (PRFs) recorded by the Tengchong seismic array (a small array consisting of nine stations) indicate only two magma chambers (Yang et al. 2013). This discrepancy could be attributed either to the data set or to the non-uniqueness of the data inversion scheme. It is difficult to obtain high-resolution images of crustal structure in this area because there are so few seismic stations deployed near the Indo-Burmese confluence, and most of these stations are located to the east of the TVF.

To provide insights into the origins of the TVF, this work aims to improve our understanding of lithospheric structure in the Tengchong area. $P$ receiver functions are a commonly used tool for exploring the crust and upper mantle. To study the TVF in detail, we first investigate patterns of crustal anisotropy using Moho-converted Pms-wave splitting analysis. We then apply the anisotropic $H-\kappa$ stacking algorithm (Wen et al. 2019) to obtain the crustal thickness 
and $\mathrm{Vp} / \mathrm{Vs}$ ratio. To take full advantage of the information provided by PRFs to map Vs and explore the lithosphere, we then use a two-step inversion technique to fit high- and low-frequency PRFs separately (Peng et al. 2017, 2019) and apply the bootstrap resampling technique to estimate uncertainties in the statistical solutions (Efron \& Tibshirani 1991).

\section{GEOLOGICAL SETTING}

As shown in a simplified geological map (Fig. 1a), the N-S trending Nujiang Fault and the NE-SW trending Wanding Fault subdivide the study area into two different tectonic blocks: the Tengchong and Baoshan blocks. The western boundary of the Tengchong block lies above the subduction zone where the Indian Plate is subducted beneath Burma. The major structural feature in this area is the Sagaing Fault (Wang \& Burchfiel 1997; Wang et al. 2008). The Tengchong block is composed mainly of middle Proterozoic highgrade metamorphic rocks (Wang \& Burchfiel 1997). The TVF lies within an N-S oriented rift (Fig. 1a), and comprises a total of 68 volcanoes and 145 hot springs. Twenty-five of the 68 volcanoes have a distinct geomorphic expression (Jiang 1998).

The Tengchong block experienced a complex geological evolution during the middle and late Cenozoic, and its modern tectonic framework was developed mainly by dextral shearing and clockwise rotation (Wang \& Burchfiel 1997; Wang et al. 2008). Two systems of relatively young and potentially active faults dominate this block. One is NNW- to N-trending normal faults with right-lateral components of slip. The clearest example of this fault system is the Tengchong Rift, which extends along the central part of the block. The boundaries of this rift are defined by well-developed normal faults that form steep topographic and are associated with hot springs (Wang \& Burchfiel 1997). Lava flows surround several volcanic cones and craters inside or along the edges of the rift (Wang \& Burchfiel 1997). The volcanic centres are subparallel to the $\mathrm{N}-\mathrm{S}$ orientation of the rift (Fig. 1a). The second relatively young fault system includes a series of NE-trending normal faults with a left-lateral component of slip that cross the southern part of the Tengchong block. The largest fault in this system is the Yinjiang Fault (Wang \& Burchfiel 1997; Wang et al. 2007, 2008). These NE-trending faults are smaller and younger than the N-S-oriented structures (Wang et al. 2008). In the Tengchong block, the Yinjiang Fault (F5 in Fig. 1a) marks the southern end of the Tengchong Rift, whereas the Longling-Ruili Fault (F6 in Fig. 1a) forms the southern boundary of the block (Wang \& Burchfiel 1997; Wang et al. 2008). The NE-trending faults dip mostly to the northwest and define the margins of elongate basins located in their hanging walls. Geological observations suggest that normal and left-lateral displacements along NE-trending faults were broadly contemporaneous with normal displacements along the $\mathrm{N}-\mathrm{S}$ trending faults (Wang \& Burchfiel 1997; Wang et al. 2008). This faulting pattern suggests that overall E-W extension involved lateral shearing and clockwise rotation of the crust (Wang \& Burchfiel 1997).

The Baoshan tectonic block lies between the Nujiang and Lancangjiang faults (faults F1 and F3, respectively, in Fig. 1a). The bounding structures of this block are a high-grade mylonitic metamorphic belt to the northeast, and locally mylonitic faults associated with granite plutons to the east (Wang \& Burchfiel 1997). The tectonic setting of the block is highly complex owing to numerous faults that displace fold and thrust belts to form an intricate mosaic of structures. Nevertheless, the Eocene-Oligocene strata have an arcuate, convex northeastward geometry in the central part of the block. This suggests that the tectonic block experienced shortening before or during the Eocene-Oligocene, probably associated with strike-slip movement along the Nujiang Fault System (Wang \& Burchfiel 1997; Wang et al. 2008).

\section{DATA ACQUISITION}

We used seismic data recorded by 26 temporary broad-band seismic stations deployed as part of the ChinArray program (Ding \& Wu 2013) during the period from 2011 September to 2014 January, and six permanent broad-band stations (bas, lus, mzt, rst, tec and wad) that have been deployed in the study area since 2000 (Fig. 1a). The seismic stations were equipped with CMG-40T or CMG-3ESPC seismometers (Cai et al. 2016) and installed with an average spacing of $\sim 35 \mathrm{~km}$. We selected 187 earthquakes with a magnitude Ms $\geq 5.8$ at epicentral distances of $30^{\circ}$ to $95^{\circ}$ (Fig. 1b), and used the timedomain iterative deconvolution method (Ligorría \& Ammon 1999) to isolate PRFs from the $P$-wave coda generated at seismic discontinuities. To reduce the amplification of high-frequency content, we used a Gaussian low-pass filter whose bandwidth is controlled by the Gaussian parameter $\alpha$ (Langston 1979). To implement the twostep inversion procedure, we sequentially calculated low-frequency ( $\alpha=1.0)$ and high-frequency ( $\alpha=2.5$ ) PRFs for each teleseismic event. After checking each waveform to ensure data quality, we acquired 3408 pairs of PRFs, and used 2028 pairs to invert for the Vs structure of the lithosphere.

Additionally, we selected 114 earthquakes with $M_{\mathrm{s}} \geq 6.8$ occurred after 2010 at epicentral distances of $65^{\circ}$ to $165^{\circ}$ (Fig. 1c). These earthquakes were used to obtain $S$ receiver functions (SRFs) at four permanent stations ( $b a s, l u s, t e c$ and $w a d$ ) to verify the depth of the lithosphere-asthenosphere boundary (LAB) previously obtained from PRFs.

\section{METHODS}

\subsection{Pms splitting}

When a converted $P$-to- $S$ wave travels through an anisotropic layer, it will split into two perpendicular shear waves with different velocities. There are two parameters of interest: the delay time between the faster and slower split waves $(\delta t)$, which depends on the strength and thickness of the anisotropic layer, and the fast-wave polarization direction $(\varphi)$. Given a single anisotropic layer with a horizontal axis of symmetry, the arrival time of the $P$-to- $S$ phase for a subvertical incident $P$-wave at the Moho (Ps or Pms) varies systematically with the backazimuth of the incident ray, and can be expressed as follows (Rümpker et al. 2014):

$t_{\mathrm{Ps}}=t_{0}+\Delta t=t_{0}-\frac{\delta t}{2} \cos [2(\theta-\varphi)]$,

where $t_{0}$ is the Ps or Pms arrival time in the isotropic case, $\delta t$ and $\varphi$ are the splitting parameters defined above, and $\theta$ is the backazimuth of the incident ray measured clockwise from north. This equation indicates that the anisotropy obeys a characteristic degree-2 $\left(180^{\circ}\right.$ periodic) backazimuth pattern in traveltime. This periodicity is a diagnostic tool for anisotropy.

Given $t_{0}$, as well as $\delta t$ and $\varphi$, we can compute the misfit function as follows:

$S(\delta t, \varphi)=\sum_{i=1}^{N}\left(t_{\mathrm{Ps}}^{(i)}(\delta t, \varphi)-t_{\mathrm{Obs}}^{(i)}\right)^{2}$. 
This equation expresses the difference between the observed $\left(t_{\mathrm{Obs}}^{(i)}\right)$ and predicted $\left(t_{\mathrm{Ps}}^{(i)}\right)$ arrival times of the Pms phase in the $i$ th PRF waveform. Here, $N$ is the total number of PRFs. When $S(\delta t, \varphi)$ reaches the minimum value on the solution surface, the values of $\delta t$ and $\varphi$ become the optimal splitting parameters. Uncertainties affecting the splitting parameters can be estimated from the flatness of $S(\delta t, \varphi)$ at the minimum, as described by Zhu \& Kanamori (2000).

\subsection{Anisotropic $H-\kappa$ stacking}

In an isotropic layered medium, the $H-\kappa$ stacking technique can be applied to estimate the average crustal thickness $\mathrm{H}$ and the $\mathrm{Vp} / \mathrm{Vs}$ ratio (Zhu \& Kanamori 2000). In an anisotropic crust, the $P$-to- $S$ phase is divided into fast and slow waves, which in turn can be divided once more when they reverberate at the Moho, meaning that PRFs can contain more fast and slow phases. A $P$-to- $S$ phase with one $S$-wave leg means that the fast Pms-wave advances by a time $\delta t / 2$ with respect to the shear wave in the isotropic medium, while the slow Pms-wave delays by $\delta t / 2$, and so on.

Recently, Wen et al. (2019) extended the classical $H$ - $\kappa$ stacking approach (Zhu \& Kanamori 2000) to include an anisotropic crust and reverberations with only two $S$-wave legs, because other reverberations are too weak to be resolved. According to Wen et al. (2019), for given values of $H$ and $\mathrm{Vp} / \mathrm{Vs}$, the stacked amplitude of the $S$ phase at the predicted arrival time can be expressed as follows:

$$
\begin{aligned}
S(H, k)= & w_{1}\left[s\left(t_{\mathrm{Ps}}-t_{\mathrm{P}}-\frac{\delta t}{2}\right) \cos ^{2}(\theta-\varphi)\right. \\
& \left.+s\left(t_{\mathrm{Ps}}-t_{\mathrm{P}}+\frac{\delta t}{2}\right) \sin ^{2}(\theta-\varphi)\right] \\
& +w_{2}\left[s\left(t_{\mathrm{PpPs}}-t_{\mathrm{P}}-\frac{\delta t}{2}\right) \cos ^{2}(\theta-\varphi)\right. \\
& \left.+s\left(t_{\mathrm{PpPs}}-t_{\mathrm{P}}+\frac{\delta t}{2}\right) \sin ^{2}(\theta-\varphi)\right] \\
& -w_{3}\left[s\left(t_{\mathrm{PpSs}+\mathrm{PsPs}}-t_{\mathrm{P}}-\delta t\right) \cos ^{2}(\theta-\varphi)\right. \\
& \left.+s\left(t_{\mathrm{PpSs}+\mathrm{PsPs}}-t_{\mathrm{P}}+\delta t\right) \sin ^{2}(\theta-\varphi)\right] .
\end{aligned}
$$

Here, $s(t)$ is the amplitude of PRF at the predicted time $t, w_{1}, w_{2}$ and $w_{3}$ are weight factors that depend on SNR, and $t_{\mathrm{Ps}}, t_{\mathrm{PpPs}}$ and $t_{\mathrm{PsPs}+\mathrm{PpSs}}$ are the expected arrival times of the converted phases in the isotropic case, which can be calculated by the standard method proposed by Zhu \& Kanamori (2000). The fast and slow Pms phases depend on the azimuthal variation factors $\cos ^{2}(\theta-\varphi)$ and $\sin ^{2}(\theta-\varphi)$, respectively.

\subsection{Two-step inversion}

The forward problem for PRFs is formulated as a nonlinear function of the Earth model. To linearize the problem, the function is expanded into a Taylor series (Ammon et al. 1990). From there, the reflection matrix method (Kennett 1983) allows us to calculate the response seismogram of the medium. The efficient algorithm of Randall (1989) can be used to calculate the differential seismogram. The singular-value decomposition technique allows computation of the inverse matrix and solution of the inverse problem using a leastsquares approach.

However, PRF modelling depends largely on the choice of the initial model because of the strong nonlinearity of the problem (Ammon et al. 1990). To overcome this, Peng et al. (2017) developed a two-step inversion procedure based on the linear inversion programs of Ammon et al. (1990), in which the bootstrap resampling technique (Efron \& Tibshirani 1991) is applied to evaluate the uncertainty of the solution. Here, we also implement this twostep inversion scheme. First, we use low-frequency PRFs (filtered with $\alpha=1.0$ ) with the aim of avoiding possible scattering caused by small heterogeneities, and then a simple initial model to invert isotropic, layered shear-velocity models. Next, an overall statistical solution is determined by using the bootstrap resampling technique (Efron \& Tibshirani 1991). This statistical solution is then regarded as a new initial model to fit high-frequency PRFs (filtered with $\alpha=$ $2.5)$ and thus obtain new velocity models. From there, the same resampling process is executed again to determine the optimal $S$-wave velocity structure below each station.

Any inversion process involves an inherent non-uniqueness, as the results depend mainly on the initial model. As a priori information in this work, we consider the average crustal $\mathrm{Vp}$ velocity obtained by seismic sounding, as well as the $\mathrm{Vp} / \mathrm{Vs}$ ratio and crustal thickness determined by the $H-\kappa$ stacking algorithm. All of these considerations provide valuable $a$ priori information to reduce dependency on the initial model (Peng et al. 2017, 2019).

\section{RESULTS}

\subsection{Pms splitting-based anisotropy}

To remove the effect of epicentral distance on Pms arrival times, all individual PRFs were moveout corrected to a reference epicentral distance of $67^{\circ}$ (Dueker \& Sheehan 1998) using the IASP91 model (Kennett \& Engdahl 1991). To compensate for the azimuthal coverage of incident seismic rays, PRFs were stacked within a $10^{\circ}$ bin along the backazimuth direction. As an example, Fig. 2(a) shows the azimuthal gather of radial receiver functions at the permanent broad-band bas station, which has been installed in the Baoshan block since 2000 (Fig. 1a). There is good azimuthal coverage on account of the long recording time. The arrival time of the Mohoconverted Pms phase occurs at $\sim 5.0$ s (Fig. 2b). To fit the Pms phase arrival time, the arrival time $t_{0}$ in eq. (1) was set to the average arrival time of the Pms phases, allowing variation within the interval from $t_{0-} 0.5 \mathrm{~s}$ to $t_{0}+0.5 \mathrm{~s}$ with a time step of $0.1 \mathrm{~s}$. The grid-search scheme provides the solution or splitting vector (i.e. the splitting parameters), which we selected on the variance diagram (Fig. 2c) for the case where the sum of the squared differences between the observed and predicted arrival times of the Pms phase reaches its minimum value. The resultant splitting parameters are $0.26 \pm 0.06 \mathrm{~s}$ and $-6 \pm 7^{\circ}$. The thick-lined ellipse in Fig. 2(c) represents a measure of the uncertainty in the splitting parameters. The theoretical Pms arrival times calculated using the optimal anisotropy parameters (wavy lines in Fig. 2b) seem to fit the observed arrival times. To check the reliability of the splitting parameters, we computed the transverse receiver functions (Fig. 2d), and then rotated the radial and transverse components into the fast and slow components, respectively. As shown in Figs 2(e) and (f), the fast and slow Pms waves arrive at $\sim 4.8$ and $\sim 5.06 \mathrm{~s}$, respectively, indicating a high level of coherence in the results.

In general, the temporary stations have shorter recording periods than those of the permanent stations (e.g. the permanent bas station). To demonstrate the reliability of the Pms splitting results, we provide two other examples related to stations 53067 and 53083. As shown in Figs 3 and 4, the Pms splitting parameters observed for the two stations are $1.22 \pm 0.10 \mathrm{~s}$ and $-4 \pm 2^{\circ}$, and $1.03 \pm 0.09 \mathrm{~s}$ and $44 \pm 3^{\circ}$, respectively (Figs $3 \mathrm{c}$ and $4 \mathrm{c}$ ). The theoretical and observed 
(a)

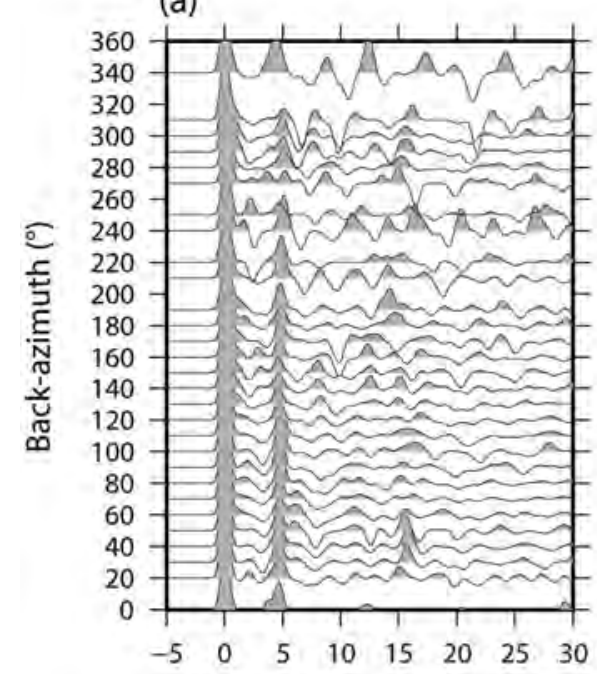

Time (s) (b)

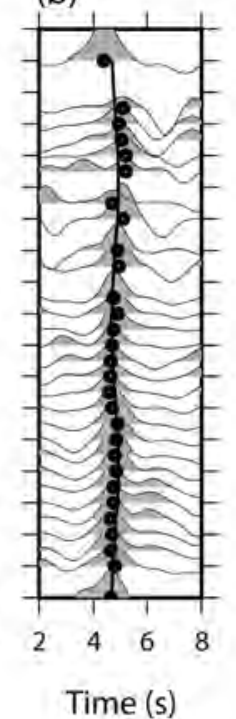

(c)

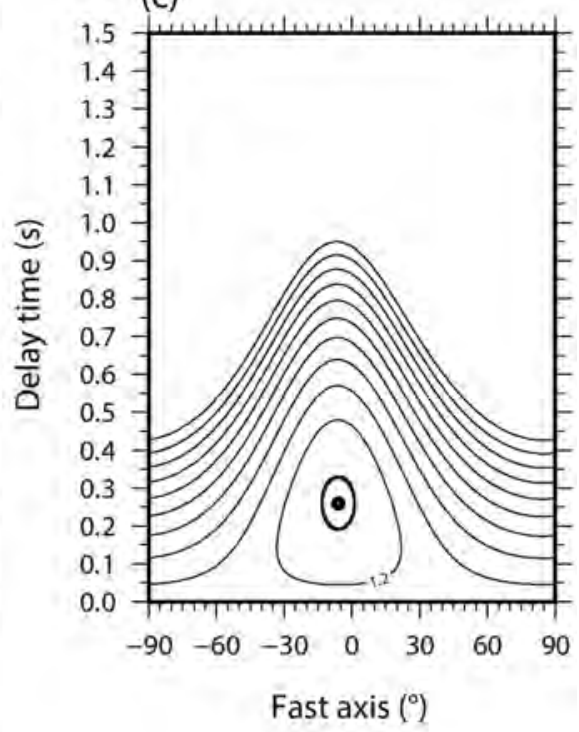

(d)

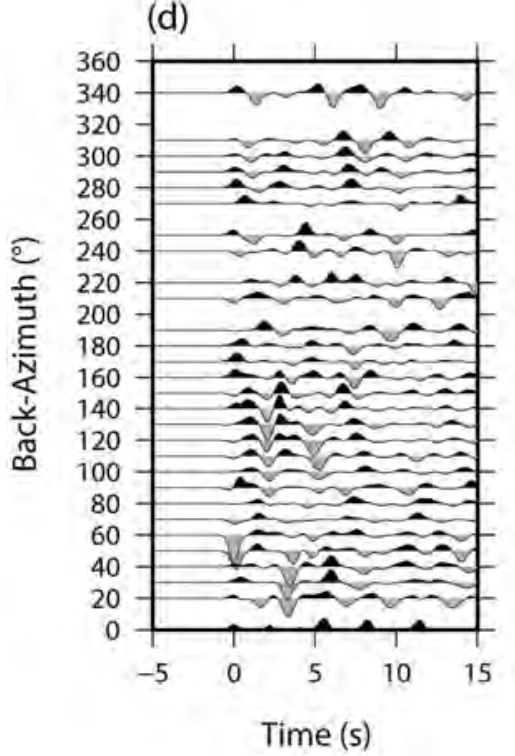

(e)

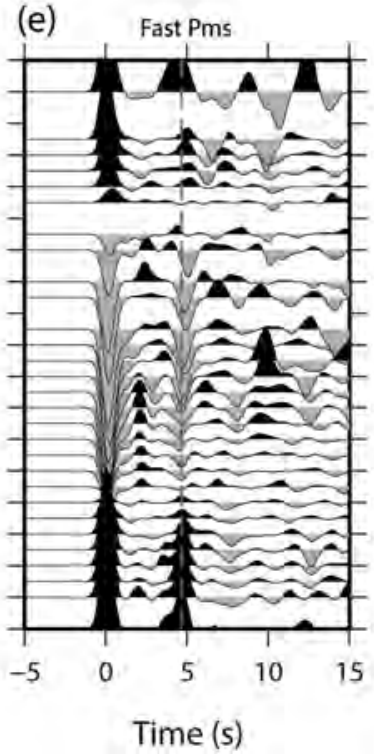

(f)

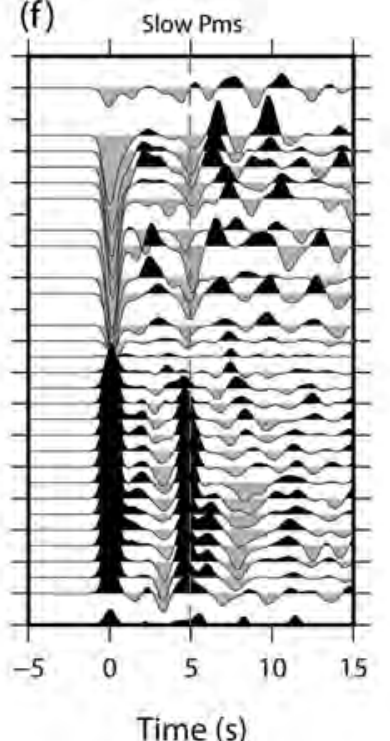

Figure 2. Pms-wave splitting analysis for the permanent broad-band bas station (Fig. 1a). (a) Azimuthal gather of radial receiver functions. (b) Enlarged view of Pms arrivals times at $\sim 5 \mathrm{~s}$ (black dots mark the energy peaks). The wavy line gives the theoretical Pms arrival times calculated using the optimal anisotropy parameters. (c) Traveltime variance diagram for splitting parameters on a searching grid; the thick-lined ellipse provides a measure of the uncertainty in the splitting parameters, and the central dot provides the optimal splitting parameters given by the minimum variance. (d) Azimuthal gather of transverse receiver functions. (e) Uncorrected fast-component receiver functions. (f) Uncorrected slow-component receiver functions.

arrival times of the Moho-converted Pms phase are comparable (Figs $3 b$ and $4 b$ ). Fast and slow Pms waves arrive, respectively, shortly before and shortly after $5.0 \mathrm{~s}$ in both cases (Figs 3e \& $\mathrm{f}$ and $4 \mathrm{e} \& \mathrm{f}$ ), again reflecting the high level of consistency in the results. The $\sim 1 \mathrm{~s}$ split time may seem long as it is comparable with the SKS splitting time (Kong et al. 2018). Nevertheless, the isolated fast and slow Pms phases at the two stations show that the lag time for all backazimuths is consistent (Figs $3 \mathrm{e} \& \mathrm{f}$ and $4 \mathrm{e} \&$ f), suggesting that the splitting time at the two stations should be reliable.

Owing to the shorter period of operation of the temporary stations, there is an azimuthal coverage gap in the range of $\sim 170^{\circ}-240^{\circ}$ (Figs 3a and $4 \mathrm{a}$ ), making the coverage poorer than for the permanent bas station. Nonetheless, according to previous studies (Zheng et al. 2018), poor azimuthal coverage occurs when the number of stacked traces is less than 12 of the 36 possible traces, or when there is a gap of $180^{\circ}$ or greater in the azimuthal coverage, which will result in larger uncertainties. Theoretically, an azimuthal range of $180^{\circ}$ can meet the fitting conditions owing to the presence of degree-2 $\left(180^{\circ}\right.$ periodic) azimuthal variation in arrival time. In our case, we counted more than 18 stacked traces.

We obtained a total of 32 estimations of anisotropy from the stations covering the study area. The results show delay times varying between 0.19 and $1.22 \mathrm{~s}$, with a mean of $0.48 \pm 0.07 \mathrm{~s}$, and fast-wave polarization directions (FPDs) with dominant NE-SW orientations (Fig. 5a). However, FPDs rotate to NW-SE along the Yinjiang Fault (F5 in Fig. 1a), where they are subperpendicular to fault strike. The polarization directions are reasonably consistent with GPS vectors 
(a)

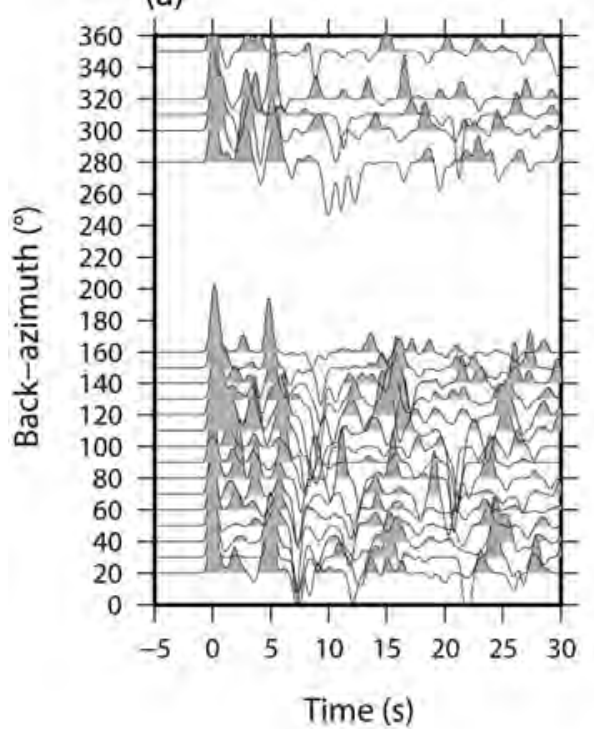

(b)

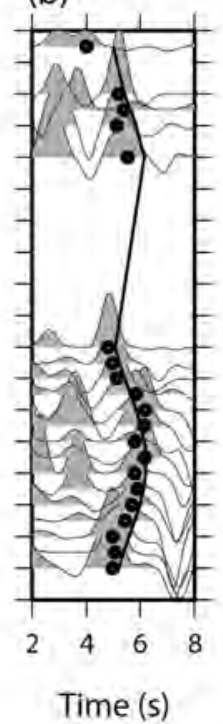

(c)

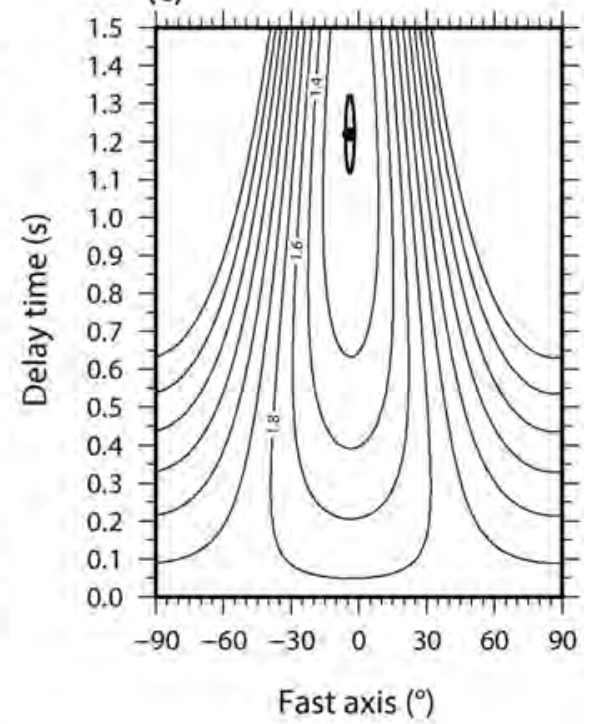

(d)

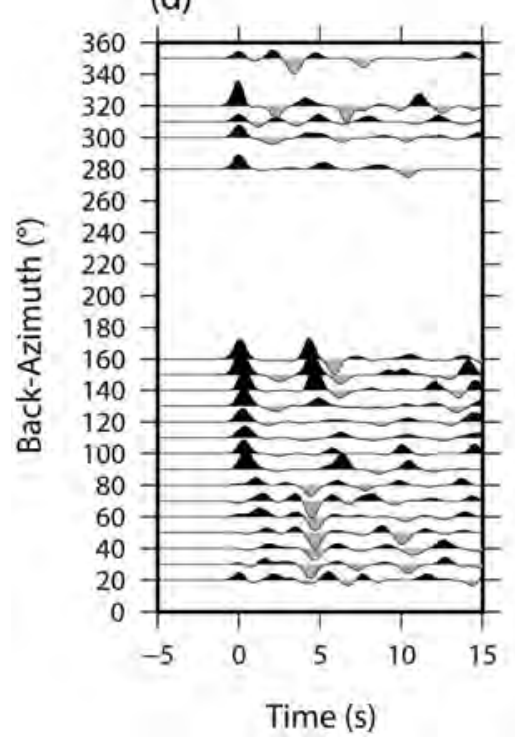

(e)

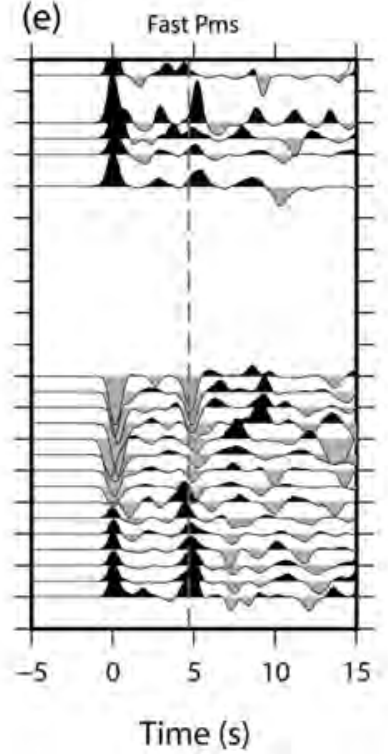

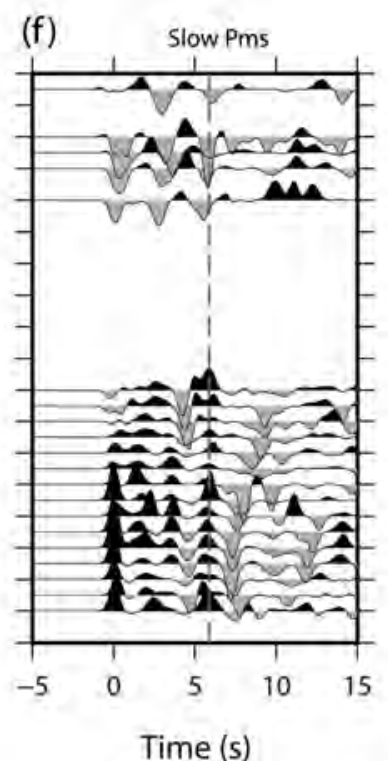

Figure 3. Plots are the same as Fig. 2 but for station 53067.

and the regional maximum compressive stress directions deduced from focal mechanism solutions (Fig. 5b) calculated for earthquakes with Ms $\geq 4.0$ that occurred in the study area from 1965 to 2017 .

\section{$5.2 \mathrm{Vp} / \mathrm{Vs}$ ratio and crustal thickness}

After application of the moveout correction to a reference distance of $67^{\circ}$, all individual PRFs at station bas were stacked in a single trace (Fig. 6a, top). In addition to the Pms phase at $\sim 5 \mathrm{~s}$, reverberation multiples PpPms and PpSms + PsPms appear at $\sim 15 \mathrm{~s}$ and $\sim 20$ s, respectively (Fig. 6a). Using the previously determined Pms splitting parameters, we applied the anisotropic $H-\kappa$ algorithm to all original PRFs recorded at station bas and obtained an optimal $\mathrm{Vp} / \mathrm{Vs}$ ratio of 1.76 and a crustal thickness of $38.6 \mathrm{~km}$ on the contour map of normalized stacked amplitudes (Fig. 6b). As the maximum amplitude is centred on a very small region (thick ellipse in Fig. 6b), the uncertainty in these results is small.
We obtained up to 32 values of $\mathrm{Vp} / \mathrm{Vs}$ in the study area, which vary from 1.68 to 1.90 (Fig. 6c). The most prominent feature is an alignment of high $\mathrm{Vp} / \mathrm{Vs}$ values distributed from north to south along the chain of volcanic cones. The rest of the area shows moderate $\mathrm{Vp} / \mathrm{Vs}$ values of $\sim 1.70-1.80$. Crustal thickness varies from 32 to $46 \mathrm{~km}$, and the Moho is deepest in correspondence with station 53068 located directly underneath the Nujiang fault (Fig. 6d).

\section{3 $S$-velocity of the crust and upper mantle}

We used the linearized inversion program developed by Ammon et al. (1990) to fit the randomly arranged radial PRFs following a two-step procedure. In our inversion scheme, the damping factor was set to 0.1 , and the SVD (singular-value decomposition) truncation fraction was set to 0.01 . The first step begins by fitting individual low-frequency PRFs ( $\alpha=1.0)$. Fig. 7(a) shows 36 PRFs with high SNR at station 53061. To start the calculation, we used an extremely 
(a)

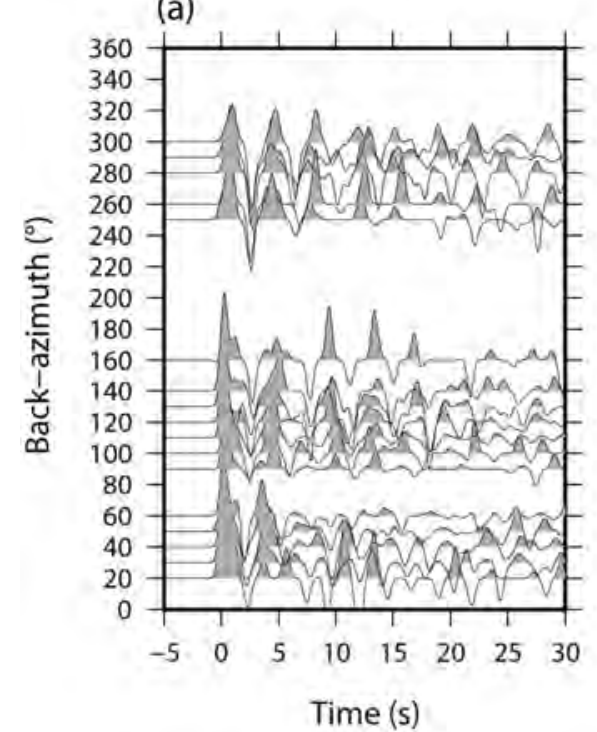

(b)

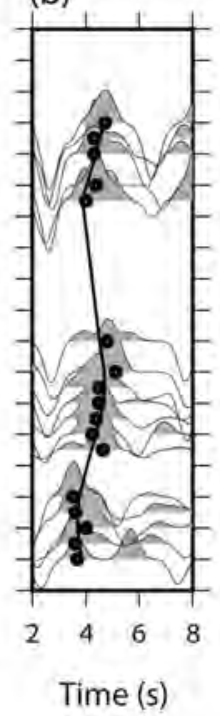

(c)

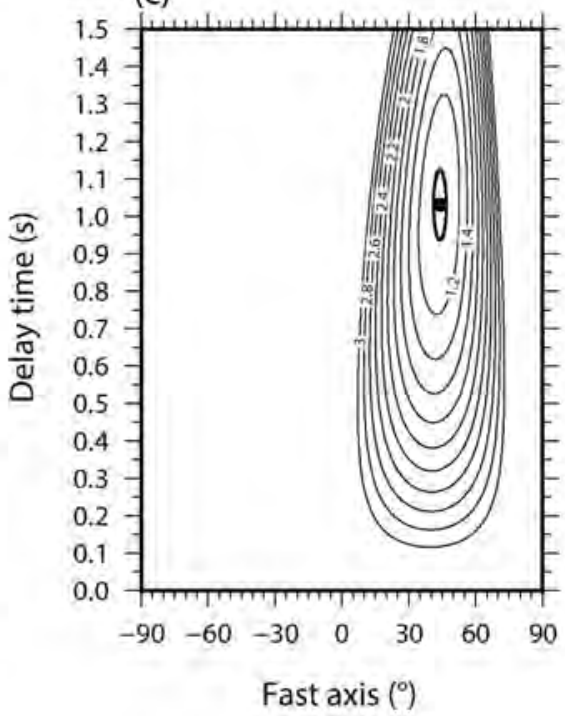

(d)

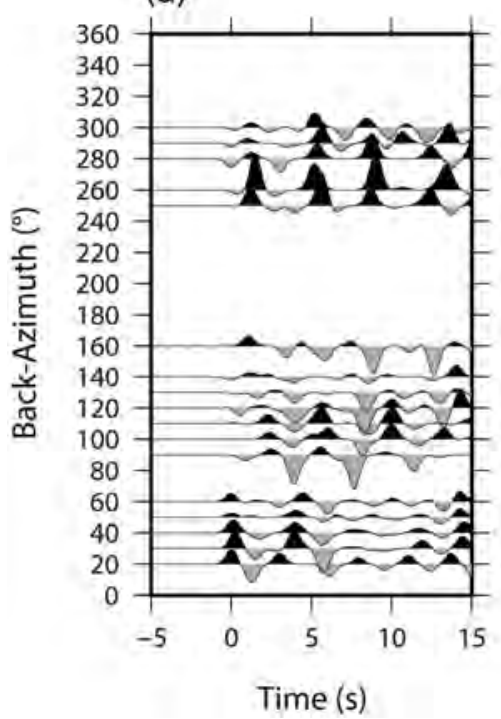

(e)

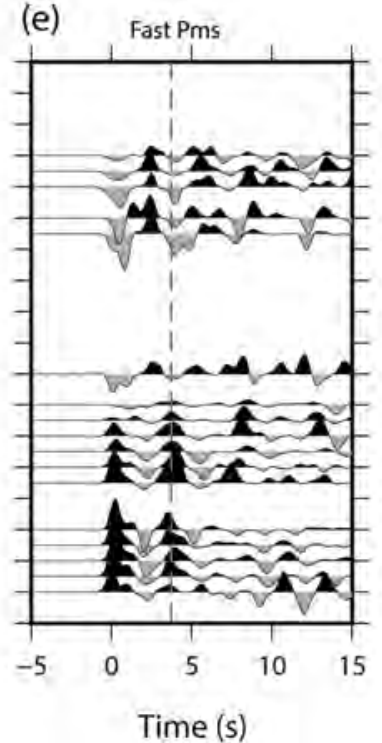

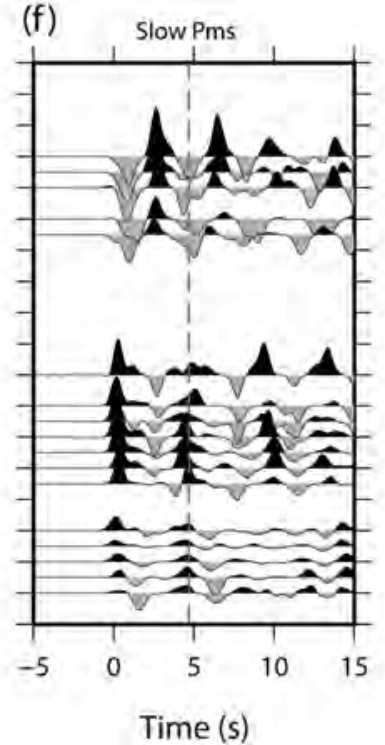

Figure 4. Plots are the same as Fig. 2 but for station 53083.

simple velocity-depth model with typical Vs values of $3.5 \mathrm{~km} \mathrm{~s}^{-1}$ (0-40 km), $4.3 \mathrm{~km} \mathrm{~s}^{-1}(40-60 \mathrm{~km})$ and $4.7 \mathrm{~km} \mathrm{~s}^{-1}$ (> $60 \mathrm{~km}$ ) (red line in Fig. 7b). As constraints (a priori information) for the initial crustal model, we considered the average Vs velocity of $3.5 \mathrm{~km} \mathrm{~s}^{-1}$ deduced from the average crustal $\mathrm{Vp}$ velocity determined by seismic sounding, as well as the $\mathrm{Vp} / \mathrm{Vs}$ ratio and the Moho depth obtained using the anisotropic $H-\kappa$ algorithm (Wen et al. 2019). Density was calculated using the empirical relationship of Berteussen (1977). Fig. 7(b) shows the obtained set of $S$-velocity models comprising 4-km-thick layers. We used the bootstrap technique (Efron \& Tibshirani 1991) to constrain the ambiguity of the inversion results and extract the statistically most accurate solution (black line in Fig. 7c) within the 95 per cent confidence interval (blue band in Fig. 7c). Fig. 7(d) shows the radial receiver function synthesized using this final solution. The Pms phase and its reverberations are similar to the observed peaks in the observed waveforms, which supports the inversion result.
The second step continues with the inversion of individual highfrequency PRFs ( $\alpha=2.5$ ), adopting the previous optimal solution as the initial model. Fig. 8a shows the 36 high-frequency PRFs at station 53061, and Fig. 8(b) shows the set of re-inverted $S$-velocity models comprising 2-km-thick layers. Again, we use the bootstrap technique to obtain the final solution (black line in Fig. 8c) within the 95 per cent confidence interval (blue band in Fig. 8c). Similarly, Fig. 8(d) shows the radial receiver function synthesized from the best statistical solution. The final solution obtained after the second inversion (Fig. 8c) presents a narrower margin of error compared with the approximate solution (Fig. 7c), and therefore less ambiguity, indicating that the procedure not only gives a more refined Vs-velocity structure but also reduces the inherent uncertainty of the inversion. Furthermore, Figs 7(d) and 8(d) show that the reverberations at the Moho are weaker in high-frequency PRFs, unlike the intracrustal phases that are stronger in high-frequency PRFs. This property indicates that the fit of high-frequency PRFs can refine the intracrustal velocity structure. 
(a)

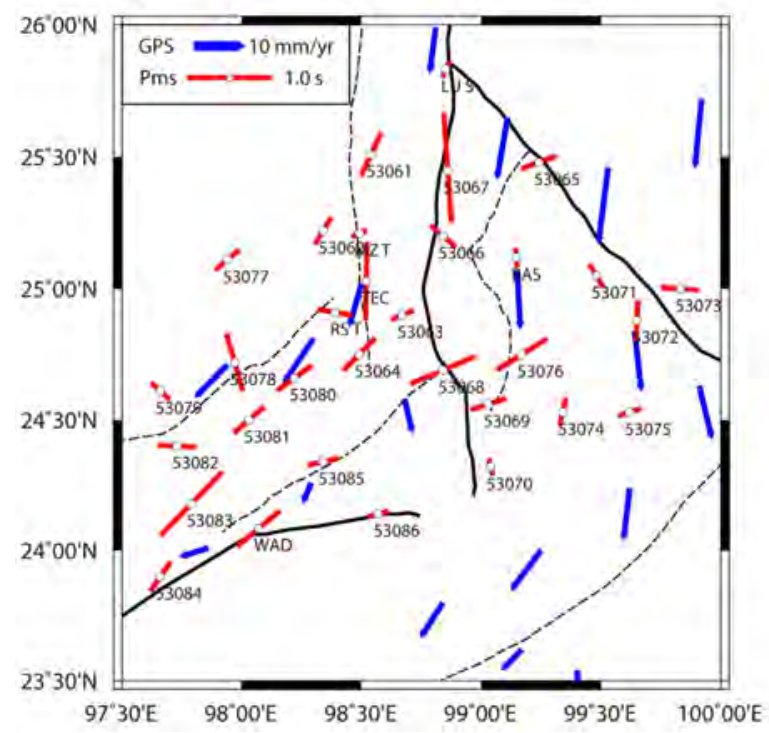

(b)

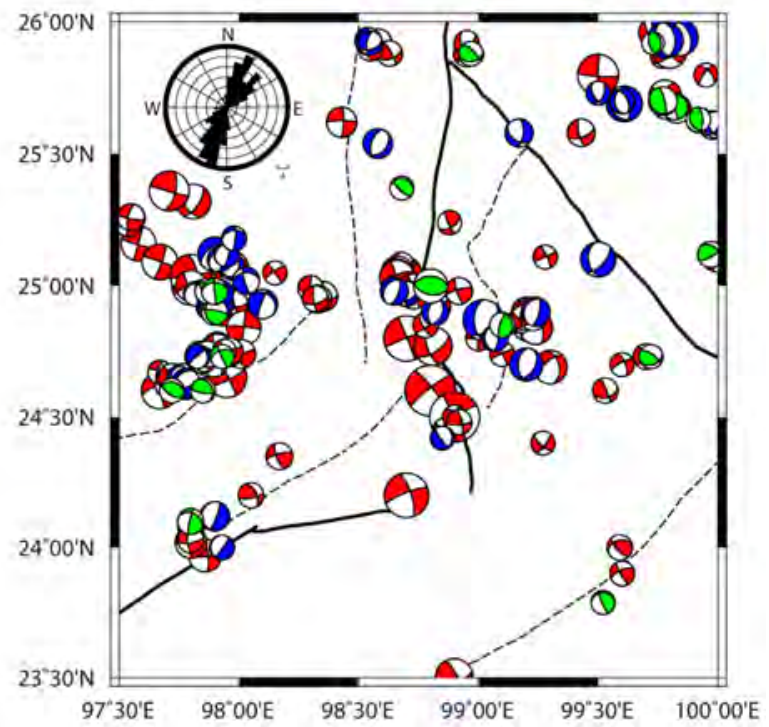

Figure 5. (a) Pms splitting vectors (segments in red) and GPS velocity vectors (Zhang et al. 2004). The fast-wave polarization direction is relative to the north, and the length of each segment is proportional to the delay time (scale in the top-left corner). GPS observations are measured relative to the Eurasian Plate (top-left corner). Small circles represent stations identified by five-digit numbers or three-letter codes. Thick lines and thin dashed lines represent major and regional faults, respectively. (b) Focal mechanism solutions calculated for earthquakes of magnitude $M_{\mathrm{s}} \geq 4.0$ that occurred in the study area during the period from 1965 to 2017. The rose diagram (top-left corner) shows the maximum horizontal compressive stress.

Finally, we obtained the Vs-velocity structure at 32 stations. We used these individual Vs-velocity models and applied GMT software (Wessel \& Smith 1998) to carry out spline interpolation to obtain the 3-D model. Values next to margins may not be reliable and were therefore not considered in the analysis. Several horizontal sections at depths of 2, 14, 24, 30, 44 and $60 \mathrm{~km}$ show velocity variations both laterally and with depth (Fig. 9). At $2 \mathrm{~km}$ depth, a relatively high-velocity $\mathrm{N}-\mathrm{S}$ oriented anomaly is observed along the volcanic chain, which is probably related to solidified igneous intrusions near the surface (Wang \& Burchfiel 1997; Wang et al. 2007). At $14 \mathrm{~km}$ depth, Vs is distributed in several strips, which are morphologically consistent with the N-S and NE-SW trending faults. At depths of 24 and $30 \mathrm{~km}$, the low velocities seem to converge on an $\mathrm{N}-\mathrm{S}$ oriented body within the lower crust. In particular, at a depth of $30 \mathrm{~km}$, the body extends across the entire northern part of the study area. At mantle depths of 44 and $60 \mathrm{~km}$, low velocities are observed only within a small area in the Baoshan block around stations bas and 53065, indicating that there is no extensive low-velocity body.

To illustrate the Vs-velocity structure beneath the Tengchong and Baoshan tectonic blocks, Fig. 10(b) shows an E-W vertical cross-section along latitude $\sim 25^{\circ} \mathrm{N}$. An extensive intracrustal lowvelocity zone (LVZ) is observed beneath several stations close to the volcanoes, which extends down to $\sim 30 \mathrm{~km}$ depth. In the Baoshan tectonic block, another LVZ is observed within the middle-lower crust, which extends westwards and reaches the middle crust below the volcanoes; this zone corresponds to moderate-to-high $\mathrm{Vp} / \mathrm{Vs}$ ratios (Fig. 6c). Velocities of up to $4.5 \mathrm{~km} \mathrm{~s}^{-1}$ characterize the mantle lithosphere. A wedge-shaped zone with velocities of $\sim 4.1-4.3 \mathrm{~km}$ $\mathrm{s}^{-1}$ extends from $\sim 38 \mathrm{~km}$ down to $60 \mathrm{~km}$ depth in the Baoshan block, revealing that the Moho in this area is defined by a gradual physical change rather than a sharp interface. This zone embedded in the upper mantle may be a common feature in tectonically active areas (Liu et al. 2014). This feature, which is observed only below stations bas and 53065 (Fig. 9), may be related to mantle upwelling.
Recently, Hua \& Lü (2019), using $7923 P$-wave arrivals recorded by 15 seismic stations, relocated several earthquakes and obtained the velocity structure beneath the TVF and adjacent areas by $P$ wave double differential tomography. Here, we reproduce the tomographic image of the crust along latitude $\sim 25^{\circ} \mathrm{N}$ (Fig. 10c) to compare with our results. The velocity sections (Figs $10 \mathrm{~b}$ and c) are quite similar to each other, except for some slight differences in the position of the LVZ, which are probably due to the relatively low lateral resolution of the tomography. This similarity and the better definition of the cross-section obtained by two-step inversion confirm the reliability of our methods and results.

\subsection{Depth of the LAB}

In Fig. 6(a), we observe a converted phase with negative polarity that arrives behind the Pms phase at $\sim 7.5 \mathrm{~s}$, and which exhibits good coherence in both the individual PRFs and in the stacked trace. The polarity of a converted $P$-to- $S$ phase provides information on the velocity contrast that generates it. In general, a positive (or negative) polarity indicates a positive (or negative) velocity gradient corresponding to velocity that increases (or decreases) with depth. Therefore, we interpret the converted phase behind the Pms phase ('Pls' near the top of Fig. 6a) as the converted phase at the LAB.

After converting individual PRFs from the time domain to the depth domain (Dueker \& Sheehan 1998) using the IASP91 model (Kennett \& Engdahl 1991), and stacking all PRFs into a single seismic trace, it is possible to determine the depth of the LAB from the stacked trace. Fig. 11(a) shows the stacked traces in the depth domain for each station in the array. Pms, Pls and the reverberation phases at the Moho can be clearly seen. In particular, the Pls phase of negative polarity that arrives behind Pms is very clear (and therefore reliable). Finally, we obtained 32 depth values for the LAB and mapped this undulating seismic boundary (Fig. 11b). The results show that the thinnest lithosphere $(\sim 55 \mathrm{~km})$ occurs in the southern 

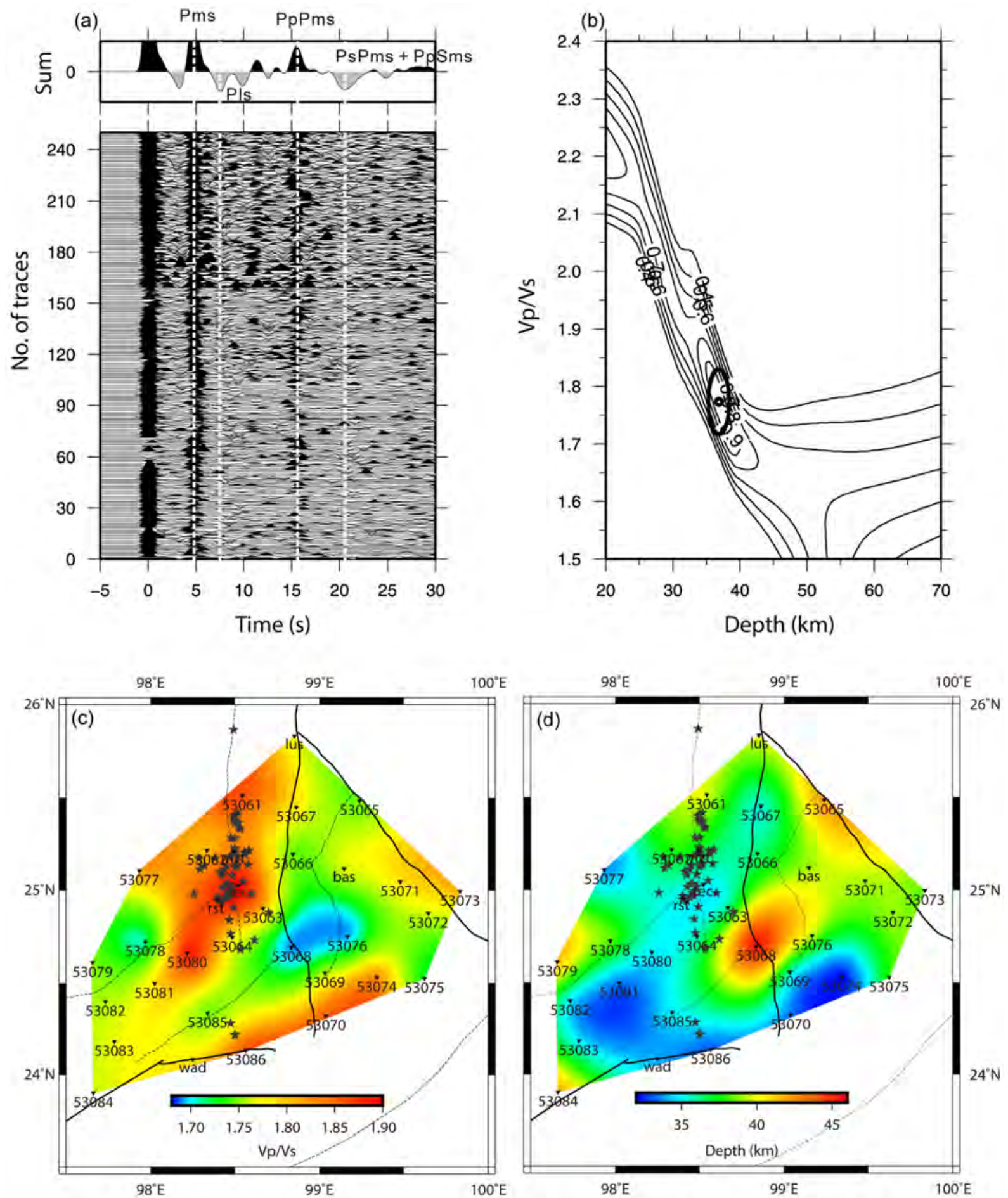

Figure 6. Anisotropic $H-\kappa$ stacking scheme, Vp/Vs ratio and crustal thickness for the study area. (a) Individual PRFs and stacked waveform at the permanent broad-band bas station after moveout correction to a reference epicentral distance of $67^{\circ}$ (Dueker \& Sheehan 1998) using the IASP91 model (Kennett \& Engdahl 1991). In addition to the Moho converted Pms phase, other converted phases and their multiple reverberations (PpPms and PpSms + PsPms) can be seen on the stacked trace (top). The weak signal Pls is the converted phase at the lithosphere-asthenosphere boundary (LAB). Vertical dashed lines indicate the respective arrival times of all of these seismic phases. (b) Contour map of normalized stacked amplitudes obtained by the anisotropic $H-\kappa$ stacking algorithm applied to the original individual PRFs. The dot represents the position of the maximum stacked amplitude on the solution surface, and the thick-lined ellipse depicts the region of uncertainty for crustal thickness and Vp/Vs ratio. (c) Distribution of crustal Vp/Vs ratio in the study area. (d) Map of crustal thickness. Stars represent the positions of volcanic cones, and inverted triangles indicate the locations of stations. Thick lines and thin dashed lines depict major and regional faults, respectively. 

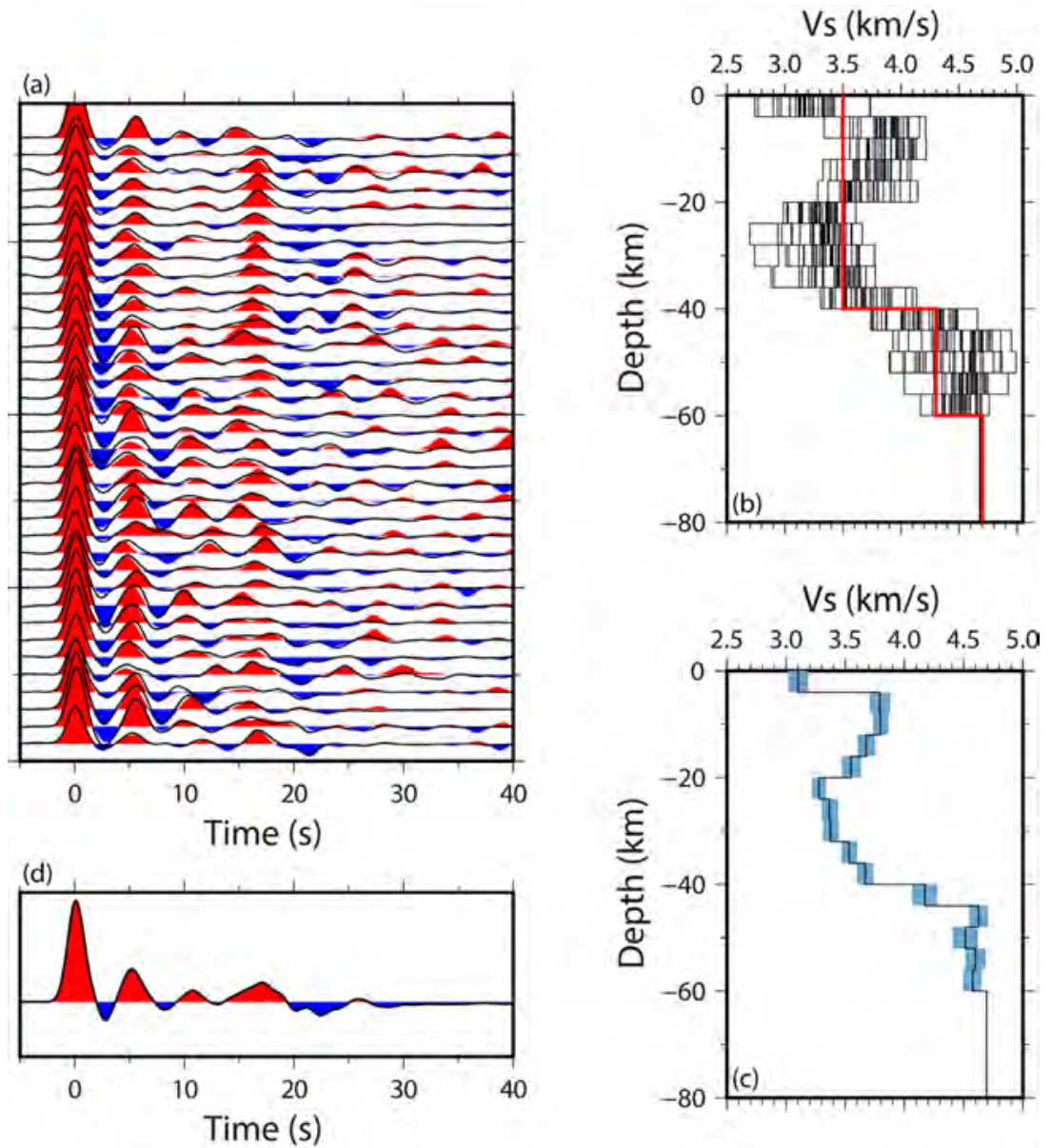

Figure 7. Inversion of randomly arranged radial PRFs recorded at station 53061 and uncertainty assessment. First stage: controlled-bandwidth Gaussian low-pass filtering with $\alpha=1.0$. (a) Fit between low-frequency PRFs (colour-filled traces) and synthetic PRFs (black curves). (b) Initial velocity model for inversion (thick red line) and set of $S$-velocity models (thin black lines). (c) The statistically most accurate solution (best $S$-wave velocity model, black line) obtained by the bootstrap technique and 95 per cent confidence intervals (blue band) for each layer. (d) Radial receiver function synthesized from the velocity model shown in (c), with a ray parameter of $0.06 \mathrm{~s} \mathrm{~km}^{-1}$.

Tengchong block, whereas the thickest lithosphere $(\sim 72-85 \mathrm{~km})$ is further north in the area where most of the volcanic cones are concentrated. The thin lithosphere determined here is comparable to that documented by Kong et al. (2018), who determined a lithospheric thickness of around $50 \mathrm{~km}$ in the Indochina block using the litho1.0 crust and lithosphere model (Pasyanos 2014).

\subsection{Identifying the LAB using SRFs}

The lithosphere and asthenosphere are first-order features in geodynamic models, but the boundary between them is commonly difficult to determine owing to its locally weak seismic impedance (Kind et al. 2012). In recent years, many methods have been developed to explore lithospheric structure along the southeastern margin of Tibet, including $P$-wave traveltime tomography (Lei et al. 2009; Huang et al. 2015) and inversion of surface wave dispersion (Wu et al. 2016). Despite this, correct identification of the LAB remains a challenge because of the generally poor quality of the available data, the low resolution of the results, or the weak seismic impedance of this discontinuity (Kind et al. 2012). PRFs are a good tool for this purpose, and some successful applications of PRFs to detect the LAB have been reported (Rychert et al. 2005). However, this method is limited in its detection of interfaces in the mantle lithosphere, due to interference between converted phases at the
LAB and strong reverberations at the Moho. PRFs can be used to explore the LAB only in special cases like a thin lithosphere $(<100 \mathrm{~km})$, because in such cases the $P$-to- $S$ phase generated at the LAB can arrive earlier than the PpPms reverberation from the Moho. On the western side of the Red River Fault (upper-left corner in Fig. 1a), local and teleseismic data sets reveal a low-velocity structure that extends from the subsurface to 300-400 km depth (Li et al. 2008; Lei et al. 2009; Huang et al. 2015). Although these previous results did not resolve the depth of the LAB, they all suggest the existence of a thin lithosphere.

In this context, SRFs should be a useful tool for overcoming the problem because of the $S$-to- $P$ converted phase arriving earlier than the incident $S$ phase and therefore separating from later $S$ reverberations (Yuan et al. 2006). The $S$ receiver-function-based method has the advantage of being free of multiple reflections, making it suitable for studying seismic discontinuities at lithospheric and asthenospheric depths. To compare the results obtained with PRFs to those obtained with SRFs, we used the aforementioned $M_{\mathrm{s}} \geq 6.8$ earthquakes that occurred at epicentral distances of $65^{\circ}$ to $165^{\circ}$ since 2010 (Fig. 1c) to isolate SRFs at four permanent stations. To display SRFs in the same way as PRFs, the time axis of the SRFs was reversed so that the converted phases appear behind the incident wave. We also reversed the amplitudes of SRFs, meaning that a positive amplitude indicates a positive velocity gradient with 
(a)

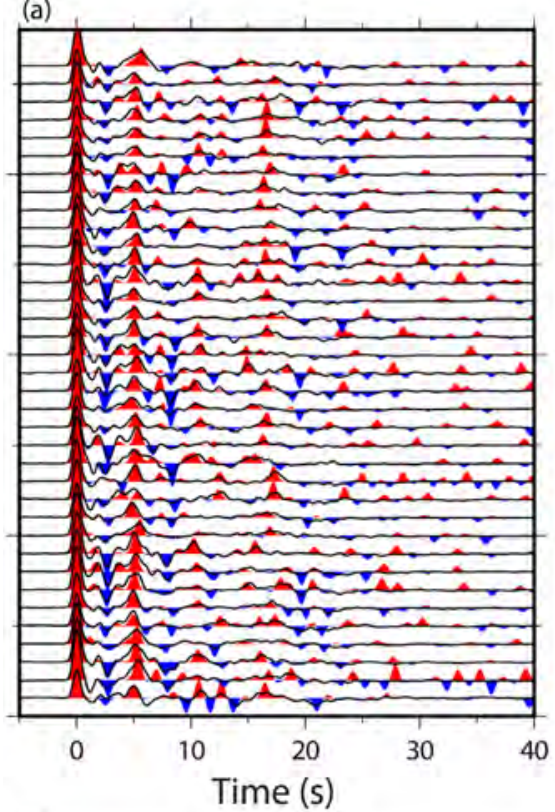

(d)

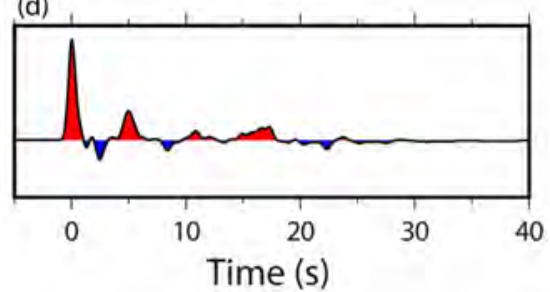

Vs $(\mathrm{km} / \mathrm{s})$

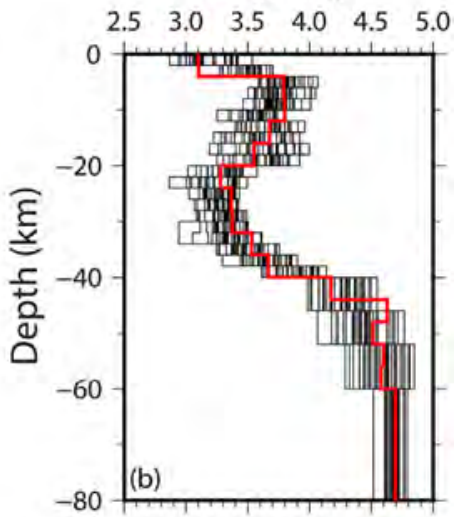

Vs $(\mathrm{km} / \mathrm{s})$

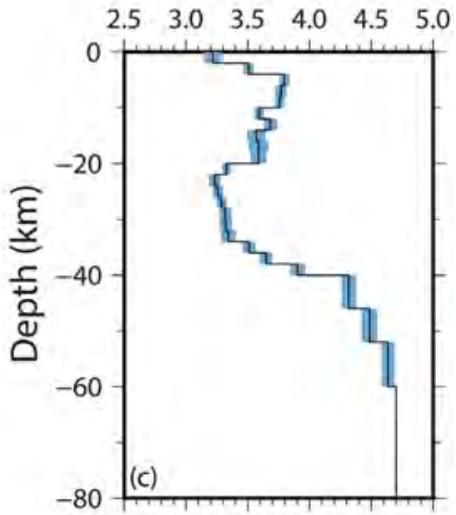

Figure 8. Inversion of randomly arranged radial PRFs recorded at station 53061 and uncertainty assessment. Second stage: controlled-bandwidth Gaussian low-pass filtering with $\alpha=2.5$. Figure panel descriptions are the same as Fig. 7.

depth. All waveforms were shifted from the time domain to the depth domain using the IASP91 model (Kennett \& Engdahl 1991). Fig. 12 shows the individual and stacked waveforms at the four reference stations (bas, lus, tec and wad), as well as the Smp and Slp phases converted at the Moho and LAB, respectively. The coherence of all of these phases is clear, especially Slp in the stacked traces. The depths of the LAB indicated by SRFs are 73 (bas), 72 (lus), 70 (tec) and $80 \mathrm{~km}(\mathrm{wad})$, compared with 71, 69, 76 and $63 \mathrm{~km}$ given by PRFs (Fig. 11b). Except for the wad station, where the discrepancy reaches $17 \mathrm{~km}$, the results deduced from the PRFs and SRFs agree quite well. The cause of the discrepancy at the wad station could be that SRFs sample a much wider area than PRFs (Fig. 13), and thus the converted phases generated by a laterally heterogeneous structure could contaminate the converted phase at the LAB. Theoretically, SRFs should resolve a $10 \mathrm{~km}$ variation in the depth of the LAB (Li et al. 2007). In fact, the dominant period of SRFs is longer than that of PRFs, so we can assume that the accuracy achieved in detecting the LAB is greater using PRFs compared with SRFs.

\section{DISCUSSION}

\subsection{The Vp/Vs ratio in the TVF}

Poisson's ratio is a key elastic constant that can be evaluated from the $\mathrm{Vp} / \mathrm{Vs}$ ratio and can provide important constraints on the mineralogy and composition of the crust (Christensen 1996; Owens \& Zandt
1997). In the $H-\kappa$ stacking algorithm (Zhu \& Kanamori 2000), the crustal $\mathrm{Vp} / \mathrm{Vs}$ ratio depends on the delay time between the $P$-to$S$ phase and multiple reverberations. Although crustal azimuthal anisotropy can affect the delay time of the conversion phases, the anisotropic $H-\kappa$ stacking algorithm is able to compensate for these effects (Wen et al. 2019). Nonetheless, the reverberations caused by a low-velocity sedimentary layer can partially or totally mask the Pms phase and its multiples, and can therefore lead to an error in the $H-\kappa$ results. However, in our case, the Pms phase and its reverberations can be easily distinguished at each station.

Even though low Vs velocity is observed in the lower crust below some stations, the crustal $\mathrm{Vp} / \mathrm{Vs}$ ratio is close to the global average of 1.73 (Fig. 6c). The reason for this may be that the thickness of the low-Vs-velocity layer is too small to affect the $\mathrm{Vp} / \mathrm{Vs}$ ratio. Our results also demonstrate the existence of a high $\mathrm{Vp} / \mathrm{Vs}$ ratio of $>1.85$ (Fig. 6c) and a low-velocity anomaly in the middle to lower crust beneath the TVF (Figs 9 and 10). However, Wang et al. (2017) did not observe such high Vp/Vs values in the TVF, despite using many PRFs recorded at 141 permanent stations and 785 temporary stations in southwest China, possibly because those authors used a different method to calculate $\mathrm{Vp} / \mathrm{Vs}$ values. High values of $\mathrm{Vp} / \mathrm{Vs}$ may also be associated with mafic crust. However, mineral physics and field constraints suggest that a high Poisson's ratio of $>0.30$, which corresponds to $\mathrm{Vp} / \mathrm{Vs}$ values of $>1.85$, implies the existence of partial melt (Christensen 1996; Owens \& Zandt 1997). The combination of $\mathrm{Vp} / \mathrm{Vs}>1.85$, low $\mathrm{Vs}$ velocity in the crust, 


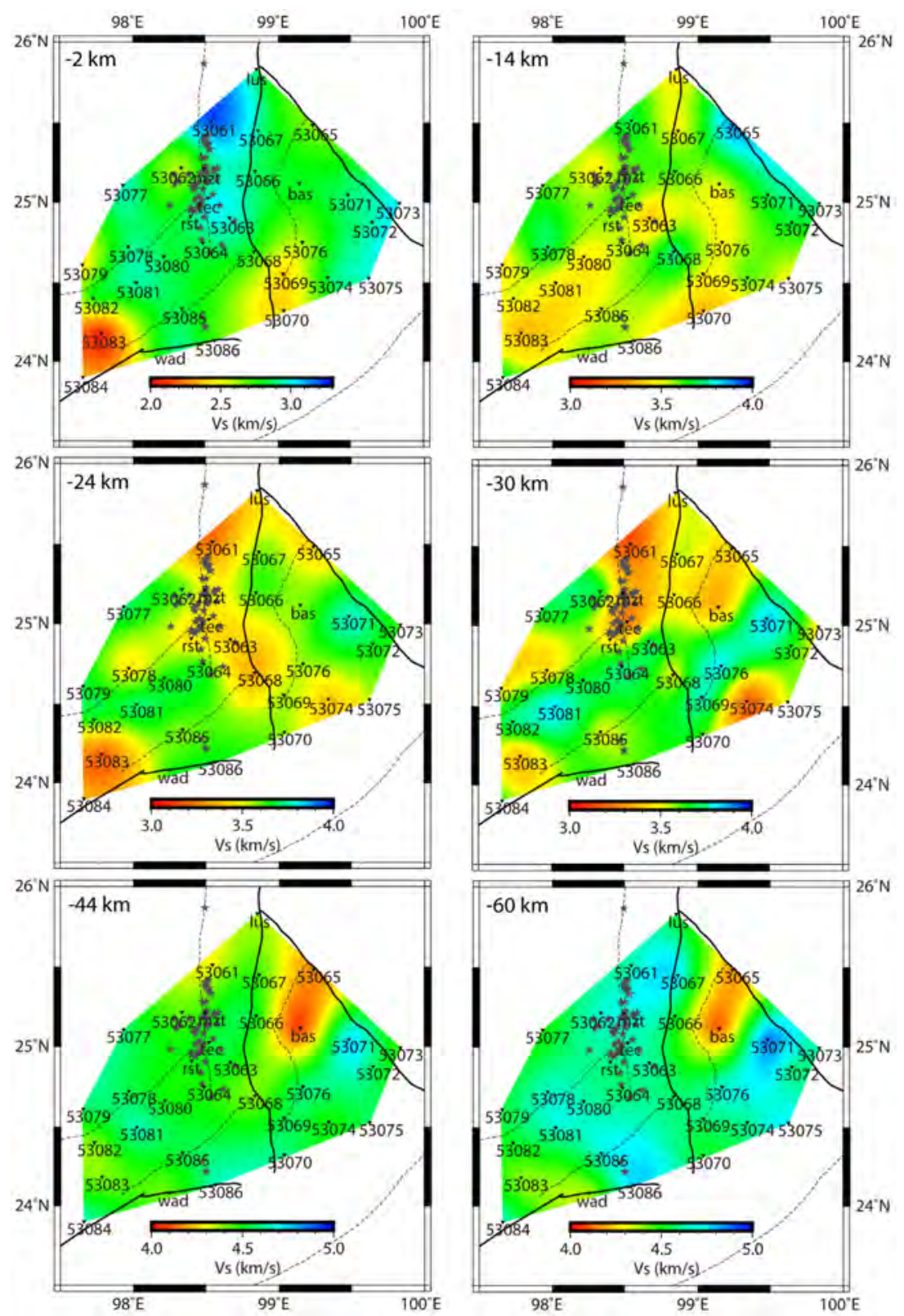

Figure 9. Mapping of Vs velocity at depths of 2, 14, 24, 30, 44 and $60 \mathrm{~km}$. Stars represent the positions of volcanic cones, and inverted triangles indicate the locations of the stations (tagged by five-digit numbers or three-letter codes, as in Fig. 1). Thick lines and thin dashed lines depict major and regional faults, respectively.

and high heat flow of $110 \mathrm{~mW} \mathrm{~m}^{-2}$ (Hu et al. 2000) indicates the existence of partial melt in the crust below the TVF. Nonetheless, the size of the affected crustal volume may not be very large because of the absence of an extensive low-velocity zone.

\subsection{An extended low-Vs-velocity zone}

According to our results, a LVZ beneath the TVF locally extends from the shallow subsurface down to the middle lower crust $(30 \mathrm{~km}$ depth), but no other significant low-velocity zones are observed in any other part of the Tengchong block (Figs 9 and 10b). Wang \& Huangfu (2004) previously detected a LVZ in the upper crust beneath the TVF. Hua \& Lü (2019) used $P$-wave double differential tomography to suggest that a LVZ beneath the TVF extends from the subsurface to the interior of the lower crust, and eastwards from the TVF to the Baoshan area near the bas seismic station (Fig. 10c). These results are broadly consistent with ours (Fig. 10b), and confirm that that the two-step inversion technique of PRFs can effectively reduce the dependence on the initial model, while the bootstrap resampling technique allows statistical refinement of the model solutions.

In theory, joint inversion of surface wave dispersion and PRFs can provide constraints on the shear-velocity structure, but the results of previous studies (Bao et al. 2015; Li et al. 2016) exhibit significant discrepancies in the position and depth of the LVZ. For instance, Li et al. (2016) suggested that a small-scale low-velocity zone exists only in the upper crust above $20 \mathrm{~km}$, and even argued for the existence of a high-velocity zone in the lower crust (30-40 km) beneath the TVF. However, Bao et al. (2015) reported only a thin 

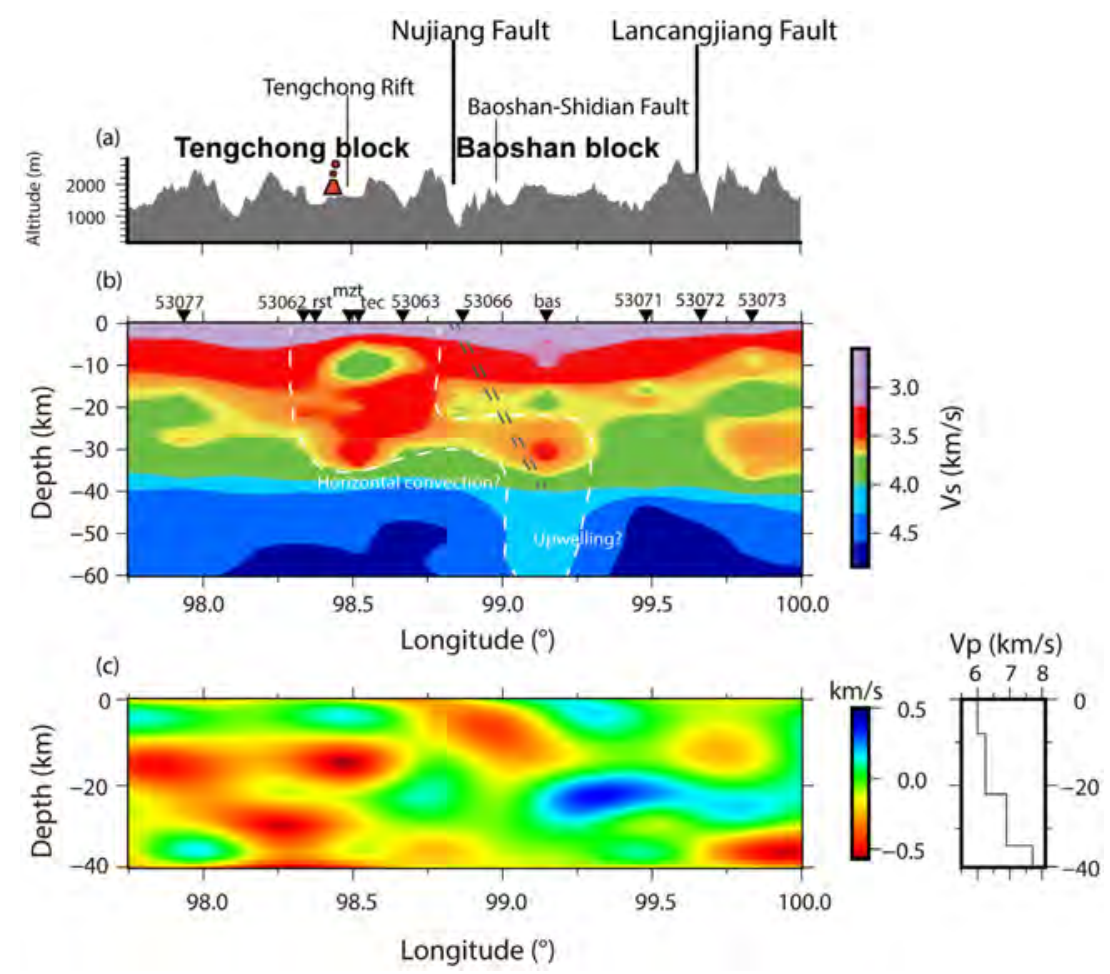

Figure 10. Vertical cross-section along profile A-A' (Fig. 1). (a) Altitude variation (topography) and tectonic blocks through which the profile passes. (b) Vs-velocity distribution with colour scale. Five-digit numbers and three-letter codes (the same as in Fig. 1) identify the positions of stations near the profile. The two parallel dashed lines show the eastward dip of the Nujiang Fault (Ye et al. 2018). (c) Image of the crust along latitude $\sim 25^{\circ} \mathrm{N}$ obtained by $P$-wave double differential tomography (Hua \& Lü 2019), for comparison with the image of Fig. 10(b).
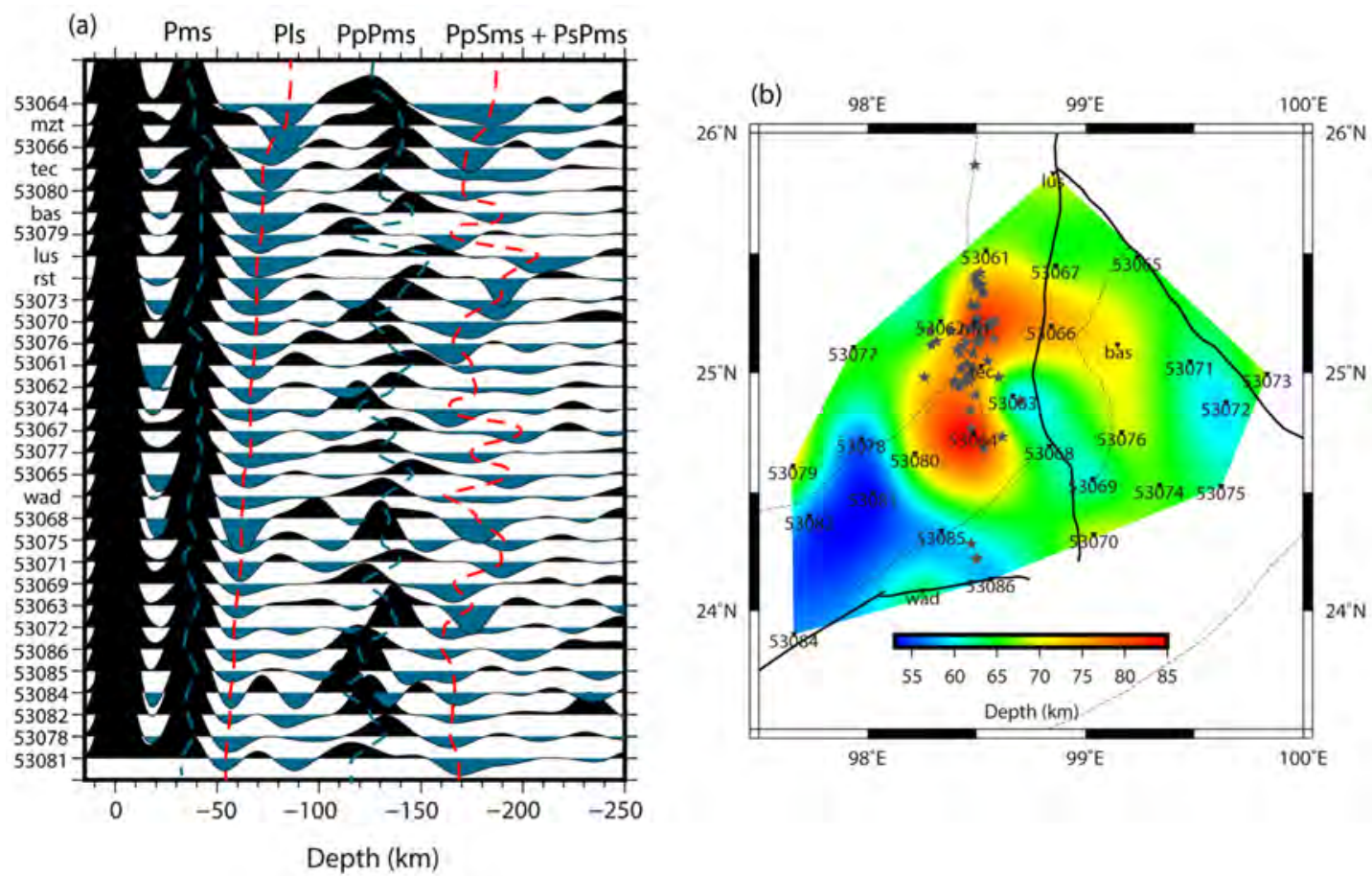

Figure 11. Analysis of PRFs and lithospheric thickness. (a) Stacked traces of low-frequency PRFs in the depth domain, obtained with $\alpha=1.0$ for each station. Pms, PpPms and PpSms + PsPms are the Moho converted phase and their multiples, respectively. The Pls phase of negative polarity is the converted phase at the LAB. The wavy dashed lines mark arrival times of the aforementioned seismic phases. (b) Depth of the LAB in the study area. Stars represent the positions of volcanic cones, and inverted triangles indicate the locations of stations (tagged by five-digit numbers or three-letter codes, as in Fig. 1). Thick lines and thin dashed lines depict major and regional faults, respectively. 

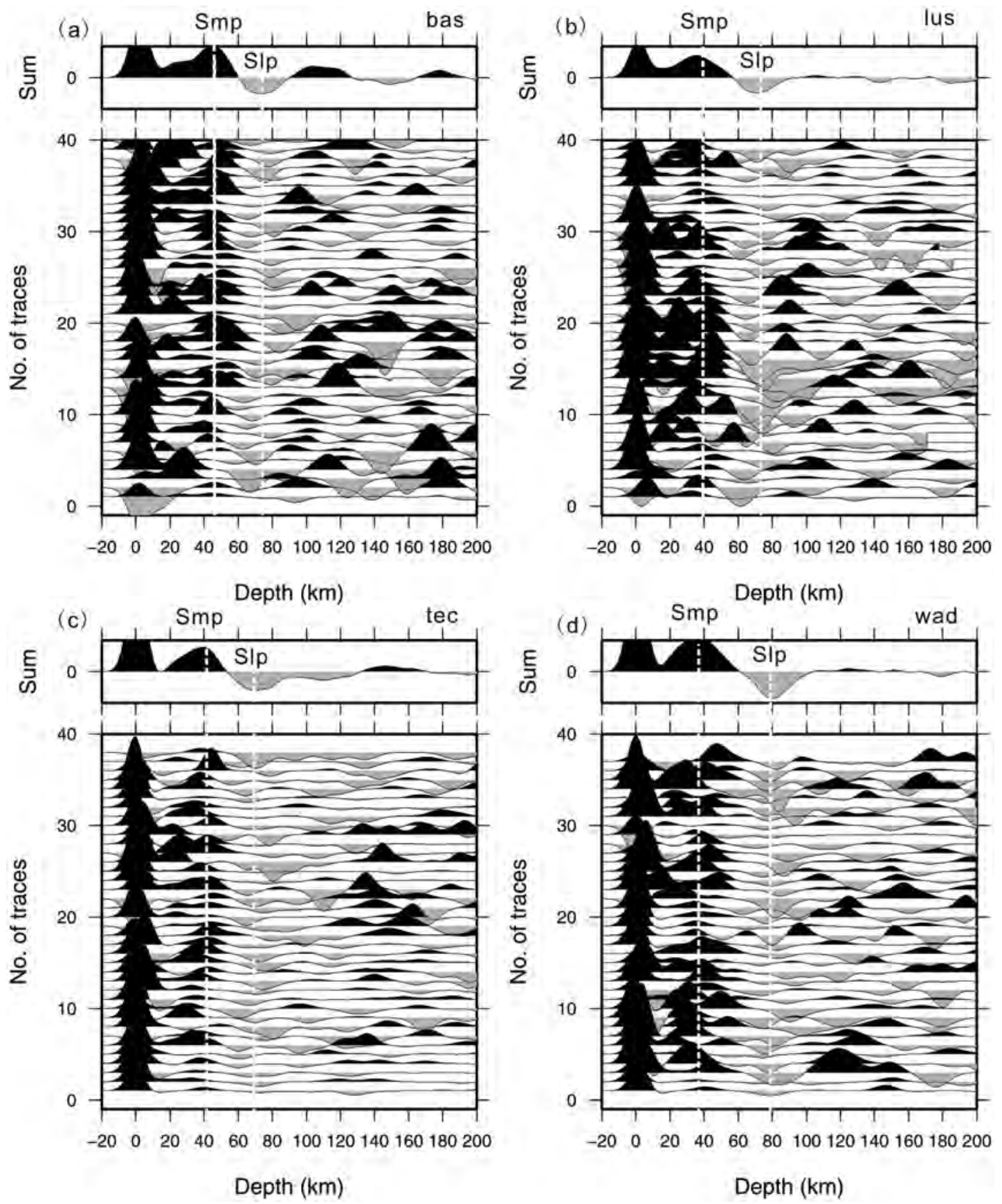

Figure 12. Individual and stacked $S$ receiver functions recorded at stations bas (a), lus (b), tec (c) and wad (d). The individual $S$ receiver functions were converted from the time domain to the depth domain using the IASP91 model (Kennett \& Engdahl 1991). Smp and Slp are the converted phases at the Moho and the LAB, respectively. The top part of each panel shows the respective stacked traces.

LVZ within the middle crust $(\sim 15 \mathrm{~km})$ below the Tengchong area, in addition to a high-velocity anomaly in the upper crust (above $10 \mathrm{~km}$ depth). Our results reveal that a LVZ extends from the subsurface to the middle-lower crust along the Nujiang Fault and partly between the Yinjiang and Longling-Ruli faults (Figs 9 and 10). We do not observe a particularly high $\mathrm{Vp} / \mathrm{Vs}$ ratio along these faults (Fig. 6c). The reason for this may be that the thickness of the low-velocity anomaly is not sufficient to affect the bulk properties of the crust. Joint inversion of Rayleigh-wave dispersion and receiver functions does not always help to eliminate ambiguity in the solutions, which can be caused by the dependence on the initial model or by the chosen analytical methods, such as the tomographic inversion of the surface wave dispersion.

High $\mathrm{Vp} / \mathrm{Vs}$ ratios, low crustal velocity and low resistivity (Ye et al. 2018), as well as other characteristics such as high heat flow (Hu et al. 2000) and the presence of active hot springs with temperatures $>90{ }^{\circ} \mathrm{C}$ (Jiang 1998), are characteristics of the crust and upper mantle below the TVF. However, in contrast to tomographic images obtained from regional and teleseismic $P$-wave traveltime data (Li et al. 2008; Lei et al. 2009; Huang et al. 2015), we do not observe an extensive low-Vs-velocity anomaly along the top of the upper mantle beneath the Tengchong block. Instead, we identify 


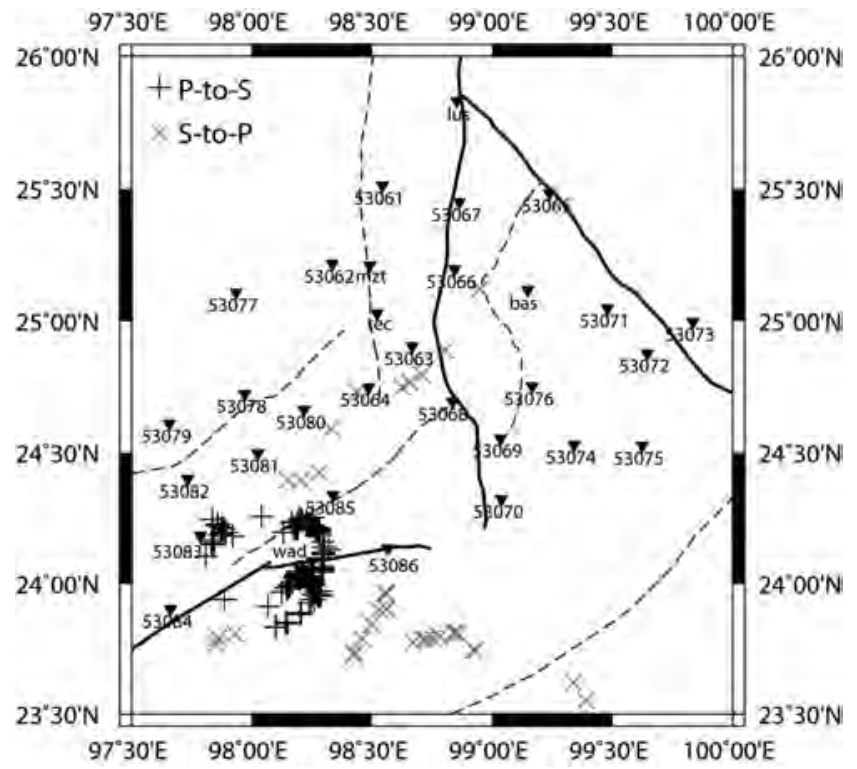

Figure 13. Piercing points of the $P$-to- $S$ and $S$-to- $P$ phases (see key in topleft corner) at a depth of $40 \mathrm{~km}$ below the $\mathrm{wad}$ station. Inverted triangles indicate the locations of stations (tagged by five-digit numbers or threeletter codes, as in Fig. 1). Thick lines and thin dashed lines depict major and regional faults, respectively.

a small low-velocity anomaly below the Baoshan block $\sim 70 \mathrm{~km}$ east of the TVF (Figs 9 and 10). A wide-angle seismic profile from Zhefang to Binchuan (Zhang \& Wang 2009) appears to show the existence of a low-velocity anomaly on top of the upper mantle beneath Baoshan (near the bas station), which is consistent with our inversion results. Pn-wave traveltime tomography supports the absence of any significant low-velocity anomaly in the uppermost mantle beneath the TVF (Lei et al. 2014), suggesting that the geophysical and geothermal features mentioned above are not directly related to the upper mantle beneath the TVF.

3-D magnetotelluric inversion (Ye et al. 2018) indicates a lowresistivity anomaly beneath the TVF, interpreted as magma chambers in the middle-lower crust. It has also revealed the presence of low-resistivity bodies in the middle-lower crust (15-30 km) beneath the Baoshan block, suggesting that crustal channel flow could take place east of the Nujiang Fault (Ye et al. 2018). The conductivity model provides evidence for magmatic intraplating in the Baoshan block but not in the Tengchong block. Peng et al. (2017) reported a substantial difference in the depth of intracrustal low-velocity bodies across the Red River Fault, and concluded that these bodies in the northern Indochina block are likely to be associated with the upper mantle rather than crustal channel flow derived from eastern Tibet.

\subsection{Mechanisms of crustal deformation}

The Indochina block began to extrude southeastward during the early stages of collision between the Eurasian and Indian plates, and moved at least $500 \mathrm{~km}$ along the Red River Fault during the Oligocene-Miocene (Tapponnier et al. 1990). The southeastern margin of Tibet has undergone significant clockwise rotation around the EHS during the last $4 \mathrm{Myr}$, as a result of southeastwards extrusion of eastern Tibet and dextral strike-slip motion along the Sagaing Fault (Wang \& Burchfiel 1997; Wang et al. 2007). In this tectonic framework, seismic anisotropy can provide critical information regarding the deformation of both young and ancient rocks. Unlike SKS-wave splitting, the Pms phase is confined to the crust and Pms splitting should therefore reflect anisotropy within the crust through which the rays travel. Our results based on Pms splitting show FPDs subparallel to GPS vectors (Fig. 5a) with a predominant NE-SW orientation, which also defines the maximum horizontal compressive stress direction (Fig. 5b). This is consistent with clockwise rotation of the entire Indochina block around the EHS. Cai et al. (2016) used the same temporary seismic array and obtained Pms splitting directions consistent with ours.

In northern Indochina, the predominant NE-SW orientation reflects modern tectonic deformation that has occurred during the past 4 Myr. Cai et al. (2016) attributed the source of crustal anisotropy in the Indochina block to the lower crust. In this case, differential movement between the relatively rigid upper crust and the ductile lower crust could generate alignment of materials parallel to the predominant direction of movement. FPDs parallel to the Wanding and Longling-Ruili faults (Fig. 5a) indicate that the observed anisotropy could be associated with fractures in shear zones. Thus, shearing within the fault zone could be a possible source of the crustal anisotropy. In the Indochina block, schist, felsic gneiss and amphibolite constitute more than 95 per cent of the metamorphic terranes west of Yunnan (Ji et al. 2000). Mineral physics experiments have shown that mica- or amphibole-bearing metamorphic rocks collected in the study area are significantly anisotropic, ant that the crust, which contains schist 15-25 km thick, could contribute up to $0.3-0.5 \mathrm{~s}$ to the observed splitting times (Ji et al. 2015). Longer splitting times at stations 53067 and 53083 could also partly be explained by local metamorphic rocks with particularly high mica or amphibole content. On this basis, we argue that the high degree of anisotropy observed in these two stations could be caused by a combination of plastic flow in the middle-lower crust and high contents of mica or amphibole in local metamorphic rocks.

Our Pms splitting results also show that some FPDs change to NW-SE along the Yinjiang Fault, where they are locally subperpendicular to the fault (Fig. 5a). Continuous rotation of the Tengchong block could be the cause of NW-SE extension affecting this area (Wang \& Burchfiel 1997). FPDs perpendicular to the Yinjiang Fault could be attributed to the E-W extensional stress induced by dextral strike-slip motion along the Sagaing Fault (Wang et al. 2007). Recently, a mechanism like this has been used to interpret the E-W fast polarization directions observed in the Indochina Peninsula (Yu et al. 2018). Previous geological studies have already suggested that the Yinjiang Fault is a normal strike-slip fault that could provide a favourable conduit for the accumulation or transmission of magma in the crust (Wang \& Burchfiel 1997; Wang et al. 2007). This faulting characteristic is consistent with the crustal deformation style inferred from Pms splitting.

Relatively small average splitting times suggest that deformation of the crust in the Baoshan tectonic block could be less pronounced in the Baoshan tectonic block than in the Tengchong block. One reason for this may be that the upwelling hot mantle causes the horizontal symmetry axis of the anisotropic medium to change, so that the Pms splitting seems to reflect a relatively weak anisotropy, especially along latitude $\sim 25^{\circ} \mathrm{N}$.

\subsection{Shallow origin of the TVF and geodynamic implications}

There are several hypotheses for the origin of the TVF. One hypothesis is that the volcanoes in Tengchong originated from dehydration of the deeply subducted Indian slab (Lei et al. 2009). Another hypothesis suggests that the TVF originates in the MTZ or close to the $410 \mathrm{~km}$ discontinuity (Xu et al. 2018). Additionally, it is possible 


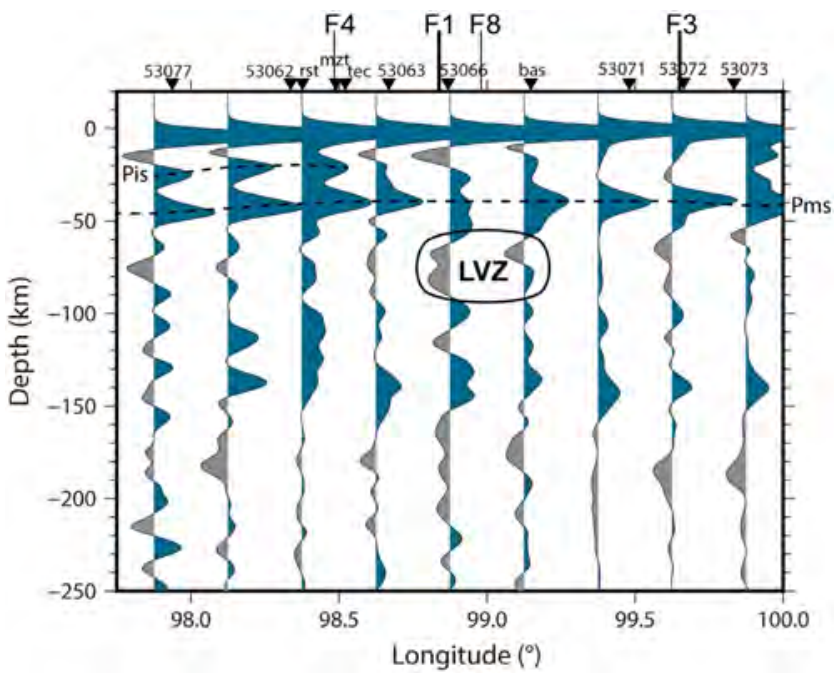

Figure 14. Set of receiver functions along profile A-A' (see Fig. 1) obtained by stacking traces in the depth domain within $0.25^{\circ}$-wide moving bins, according to the location of piercing points at $40 \mathrm{~km}$ depth. Dashed lines labelled with 'Pms' and 'Pis' denote converted phases at the Moho and Conrad interface, respectively. The abbreviation LVZ refers to a mantletype low-velocity zone. The profile passes through several faults, which are marked on top of the section: F1, Nujiang Fault; F3, Lancangjiang Fault; F4, Tengchong Rift; F8, Baoshan-Shidian Fault (see Fig. 1). Five-digit numbers and three-letter codes (the same as in Fig. 1) identify the positions of the stations close to the profile.

that a slab-tearing mechanism could contribute to the TVF, as this would allow the hottest underlying mantle to move upwards below the Tengchong area (Zhang et al. 2017). However, there does not appear to be a low-velocity zone or hot source directly beneath the TVF in the upper mantle, but $\sim 100-200 \mathrm{~km}$ to the east (Huang et al. 2015; Zhang et al. 2017; Xu et al. 2018). This distribution suggests that upwelling mantle could deviate westwards towards the base of the TVF due to rollback of the Indian slab (Zhang et al. 2017; Xu et al. 2018). However, this geodynamic model requires additional verification because of the current absence of reliable seismic evidence regarding the characteristics of the upper mantle beneath the TVF.

Starting from individual PRFs in the depth domain, we used the common-conversion-point stacking scheme (Dueker \& Sheehan 1998) to obtain a set of receiver functions along the reference profile A-A' at latitude $\sim 25^{\circ} \mathrm{N}$ (Fig. 14). The seismic traces were stacked within $0.25^{\circ}$-wide moving bins, according to the locations of the piercing points at $40 \mathrm{~km}$ depth. A positive converted phase labelled 'Pis' in Fig. 14 appears at $\sim 20 \mathrm{~km}$ and another one labelled 'Pms' at $\sim 40 \mathrm{~km}$. We interpret these phases as converted phases at the Conrad and Moho discontinuities, respectively. The Nujiang Fault (F1 in Fig. 14) apparently divides the profile into two segments: in the western segment, the Pis and Pms phases are easily distinguishable, but in the eastern segment the Pis phase is very weak (or even disappears). Very close to the position where there is a low-velocity zone embedded in the upper mantle (Fig. 10b), the wavelets of the Moho-converted Pms phase broaden slightly, suggesting that there is an irregularly shaped Moho in that region. Below this, at $\sim 60-80 \mathrm{~km}$ depth, clear polarity changes appear ('LVZ' in Fig. 14). Convincing evidence for the ascent of hot mantle in this region is the relatively small Pms splitting times along the reference profile (Fig. 5a). The ascent of hot mantle material could weaken the appearance of the Conrad discontinuity, but it could also change the symmetry axis of the anisotropic lithosphere and result in mechanically weak anisotropy. Accordingly, the low-velocity anomaly in the lower crust beneath the TVF may be caused by hot material generated in the upper mantle beneath the neighbouring Baoshan block, and not directly below the TVF.

Understanding how the low-velocity anomaly is transmitted from the Baoshan block to the Tengchong block requires further explanation. We propose an alternative mechanism in which the $\mathrm{Nu}-$ jiang Fault, which is a crustal-scale eastward-dipping boundary fault (Ye et al. 2018), reaches the base of the lithosphere and generates a favourable tectonic setting for magma intrusion into the crust. The predominant NE-SW-oriented compressive stress direction (Fig. 5b), combined with southwestward movements of the crust, are especially favourable for the transfer of hot material from the Baoshan block towards the Tengchong block. Geochemical evidence suggests that magma was generated at 27-15 Ma, and then underwent multiple stages of eruption from the late Miocene onwards at $\sim 5.5-4.0, \sim 3.9-0.9$, and $\sim 0.8-0.01 \mathrm{Ma}$ (Wang et al. 2007). Using the Hawaiian islands as a case study, Li et al. (2004) described the interaction between the Hawaiian plume and the moving lithosphere. They argued that in the centre of the hot plume material, only the lowest parts of the lithosphere are heated without substantial changes in thickness. In contrast, along the volcanic chain and away from the centre of hot material, increasing volumes of material in the lower parts of the lithosphere are heated up after 3-4 Ma, so that the depth of the LAB becomes shallower. The volcanoes in Tengchong are young from north to south (Wang et al. 2007), suggesting that the lithosphere has moved southwards or southwestwards, which is consistent with GPS vectors (Fig. 5a) and tectonic stress (Fig. 5b). Therefore, we interpret that the relatively shallow depth of the LAB in the south of the study area (Fig. 11b) may be caused by drag along the base of the lithosphere. The intense compressional environment in the Baoshan block would impede movement of magma at the base of the upper crust, consistent with the absence of volcanic activity at the surface.

\section{CONCLUSIONS}

We investigated the anisotropy of the crust and the seismic velocity structure of the lithosphere in and around the Tengchong volcanic field using PRFs isolated at 32 broad-band stations. In the Tengchong and Baoshan blocks, FPDs have a predominant NE-SW orientation and are parallel to the strike of major faults, present-day GPS vectors, and the direction of maximum horizontal compressional stress, consistent with clockwise rotation of the entire block around the EHS. However, FPDs rotate to NW-SE along the Yinjiang Fault and are perpendicular to the fault strike, which reflects the presence of normal strike-slip faults in response to E-W extensional stress induced by dextral strike-slip motion of the Sagaing Fault. The relatively small splitting times in the Baoshan block suggest that crustal deformation there is comparatively weak or that the horizontal symmetry axis of the anisotropic medium has changed.

In the TVF, we have obtained high $\mathrm{Vp} / \mathrm{Vs}$ ratios of $\sim 1.85-1.90$ (Poisson's ratio of $>0.30$ ) and low Vs velocity between 20 and $30 \mathrm{~km}$ depth, suggesting the existence of partially molten crust. However, we did not identify a large-scale low-velocity anomaly anywhere else in this block, nor an extensive low-Vs-velocity anomaly on top of the mantle below Tengchong. The low-velocity anomaly in the lower crust beneath the TVF may be caused by hot material generated in the upper mantle beneath the neighbouring Baoshan block, but not directly beneath the TVF. 
We propose that the eastward-dipping Nujiang Fault may extend to the base of the lithosphere where it creates a favourable tectonic setting for magma intrusion into the crust. The NE-SW direction of the Pms splitting vectors supports this model of transfer of hot material from Baoshan to Tengchong. In addition to its contribution to the low-velocity anomaly below the TVF, the upwelling of hot mantle beneath the Baoshan block may be the reason for the relatively shallow depth of the LAB $(\sim 55 \mathrm{~km})$ in the southern Tengchong block.

\section{ACKNOWLEDGEMENTS}

We are grateful to the China Seismic Array Data Management Center, Institute of Geophysics, China Earthquake Administration (ChinArray DMC, doi:10.12001/ChinArray.Data, http://www.chin arraydmc.cn/) for providing us with the original seismic data used in this study. The data used for this paper can be accessed at the indicated address. We also thank Drs. Yulin Hua and Yan Lü for providing us with an image of the crust obtained by $P$-wave double differential tomography. Suggestions from the journal editor and the helpful comments of two anonymous reviewers helped to substantially improve an earlier version of this paper. The National Natural Science Foundation of China provided financial support for this research work (grants 41774110, 41464003 and 41964002).

\section{REFERENCES}

Ammon, C.J., Randall, G.E. \& Zandt, G., 1990. On the nonuniqueness of receiver function inversions, J. geophys. Res., 95, 15303-15318.

Bao, X. et al., 2015. Two crustal low-velocity channels beneath SE Tibet revealed by joint inversion of Rayleigh wave dispersion and receiver functions, Earth planet. Sci. Lett., 415, 16-24.

Berteussen, K.A., 1977. Moho depth determinations based on spectralratio analysis of NORSAR long-period $P$ waves, Phys. Earth planet. Inter, 15(1), 13-17.

Cai, Y., Wu, J., Fang, L., Wang, W. \& Yi, S., 2016. Crustal anisotropy and deformation of the southeastern margin of the Tibetan Plateau revealed by Pms splitting, J. Asian Earth Sci., 121, 120-126.

Christensen, N.I., 1996. Poisson's ratio and crustal seismology, J. geophys. Res., 101, 3139-3156.

Ding, Z. \& Wu, Z., 2013. Advances of the ChinArray program, paper presented at the AGU Fall Meeting of 2013, San Francisco, CA.

Dueker, K.G. \& Sheehan, A.F., 1998. Mantle discontinuity structure beneath the Colorado Rocky Mountains and High Plains, J. geophys. Res., 103(B4), 7153-7169.

Efron, B. \& Tibshirani, R., 1991. Statistical data analysis in the computer age, Science, 253(5018), 390-395.

Helffrich, G., 2000. Topography of the transition zone seismic discontinuities, Rev. Geophys., 38(1), 141-158.

Huang, Z. et al., 2015. Mantle structure and dynamics beneath SE Tibet revealed by new seismic images, Earth planet. Sci. Lett., 411, 100-111.

Hua, Y.L. \& Lü, Y., 2019. Double differential tomography of the Tengchong volcano and adjacent areas, Chin. J. Geophys., 62(8), 2982-2990.

Hu, S., He, L. \& Wang, J., 2000. Heat flow in the continental area of China: a new data set, Earth planet. Sci. Lett., 179(2), 407-419.

Jiang, C., 1998. Distribution characteristics of Tengchong volcano in the Cenozoic era, J. Seismol. Res., 21, 309-319 (in Chinese with abstract in English).

Ji, J., Zhong, D., Sang, H. \& Zhang, L., 2000. The western boundary of extrusion blocks in the Southeastern Tibetan Plateau, Chin. Sci. Bull., 45(10), 876-881.

Ji, S., Shao, T., Michibayashi, K., Oya, S., Satsukawa, T., Wang, Q., Zhao, W. \& Salisbury, M.H., 2015. Magnitude and symmetry of seismic anisotropy in mica- and amphibole-bearing metamorphic rocks and implications for tectonic interpretation of seismic data from the southeast Tibetan Plateau, J. geophys. Res., 120(9), 6404-6430.
Kennett, B.L.N., 1983. Seismic Wave Propagation in Stratified Media, Cambridge Univ. Press, pp. 126-156.

Kennett, B.L.N. \& Engdahl, E.R., 1991. Traveltimes for global earthquake location and phase identification, Geophys. J. Int., 105(2), 429-465.

Kind, R., Yuan, X. \& Kumar, P., 2012. Seismic receiver functions and the lithosphere-asthenosphere boundary, Tectonophysics, 536-537, 25-43.

Kong, F., Wu, J., Liu, L., Liu, K.H., Song, J., Li, J. \& Gao, S.S., 2018. Azimuthal anisotropy and mantle flow underneath the southeastern Tibetan Plateau and northern Indochina Peninsula revealed by shear wave splitting analyses, Tectonophysics, 747-748, 68-78.

Langston, C.A., 1979. Structure under Mount Rainier, Washington, inferred from teleseismic body waves, J. geophys. Res., 84(B9), 4749-4762.

Lei, J., Li, Y., Xie, F., Teng, J., Zhang, G., Sun, C. \& Zha, X., 2014. Pn anisotropic tomography and dynamics under eastern Tibetan plateau, $J$. geophys. Res., 119(3), 2174-2198.

Lei, J., Zhao, D. \& Su, Y., 2009. Insight into the origin of the Tengchong intraplate volcano and seismotectonics in southwest China from local and teleseismic data, J. geophys. Res., 114(B5), B05302, doi:10.1029/2008JB005881.

Li, C., Hilst, R.D. van der, Meltzer, A.S. \& Engdahl, E.R., 2008. Subduction of the Indian lithosphere beneath the Tibetan Plateau and Burma, Earth planet. Sci. Lett., 274(1-2), 157-168.

Ligorría, J.P. \& Ammon, C.J., 1999. Iterative deconvolution and receiverfunction estimation, Bull. seism. Soc. Am., 89, 1395-1400.

Li, M., Zhang, S., Wang, F., Wu, T. \& Qin, W., 2016. Crustal and uppermantle structure of the southeastern Tibetan Plateau from joint analysis of surface wave dispersion and receiver functions, J. Asian Earth Sci., 117, 52-63.

Liu, Q.Y. et al., 2014. Eastward expansion of the Tibetan Plateau by crustal flow and strain partitioning across faults, Nat. Geosci., 7(5), 361-365.

Li, X., Kind, R., Yuan, X., Wölbern, I. \& Hanka, W., 2004. Rejuvenation of the lithosphere by the Hawaiian plume, Nature, 427(6977), 827-829.

Li, X., Yuan, X. \& Kind, R., 2007. The lithosphere-asthenosphere boundary beneath the western United States, Geophys. J. Int., 170(2), 700-710.

Ni, J.F., Guzman-Speziale, M., Bevis, M., Holt, W.E., Wallace, T.C. \& Seager, W.R., 1989. Accretionary tectonics of Burma and the threedimensional geometry of the Burma subduction zone, Geology, 17(1), $68-71$.

Owens, T.J. \& Zandt, G., 1997. Implications of crustal property variations for models of Tibetan plateau evolution, Nature, 387(6628), 37-43.

Pasyanos, M.E., Masters, T.G., Laske, G. \& Ma, Z., 2014. LITHO1.0: An updated crust and lithospheric model of the Earth, J. Geophys. Res. Solid Earth., 119, 3(8):2153-2173.

Peng, H., Hu, J., Badal, J. \& Yang, H., 2019. S-Wave velocity images of the crust in the southeast margin of tibet revealed by receiver functions, Pure appl. Geophys., 176(10), 4223-4241.

Peng, H., Yang, H., Hu, J. \& Badal, J., 2017. Three-dimensional S-velocity structure of the crust in the southeast margin of the Tibetan plateau and geodynamic implications, J. Asian Earth Sci., 148, 210-222.

Randall, G.E., 1989. Efficient calculation of differential seismograms for lithospheric receiver functions, Geophys. J. Int., 99(3), 469-481.

Royden, L.H., Burchfiel, B.C. \& Hilst, R.D. van der., 2008. The geological evolution of the Tibetan Plateau, Science, 321(5892), 1054-1058.

Rumpker, G., Kaviani, A. \& Latifi, K., 2014. Ps-splitting analysis for multilayered anisotropic media by azimuthal stacking and layer stripping, Geophys. J. Int., 199(1), 146-163.

Rychert, C.A., Fischer, K.M. \& Rondenay, S., 2005. A sharp lithosphereasthenosphere boundary imaged beneath eastern North America. Nature, 436(7050), 542-545.

Tapponnier, P. et al., 1990. The Ailao Shan/Red River metamorphic belt: tertiary left-lateral shear between Indochina and South China, Nature, 343(6257), 431-437.

Wang, C.Y. \& Huangfu, G., 2004. Crustal structure in Tengchong VolcanoGeothermal Area, western Yunnan, China, Tectonophysics, 380(1-2), 6987.

Wang, E. \& Burchfiel, B.C., 1997. Interpretation of Cenozoic tectonics in the right-lateral accommodation zone between the Ailao Shan shear zone and the eastern Himalayan syntaxis, Int. Geol. Rev., 39(3), 191-219. 
Wang, G., Wan, J., Wang, E., Zheng, D. \& Li, F., 2008. Late Cenozoic to recent transtensional deformation across the Southern part of the Gaoligong shear zone between the Indian plate and SE margin of the Tibetan plateau and its tectonic origin, Tectonophysics, 460(1-4), 1-20.

Wang, W., Wu, J., Fang, L., Lai, G. \& Cai, Y., 2017. Crustal thickness and Poisson's ratio in southwest China based on data from dense seismic arrays, J. geophys. Res., 122(9), 7219-7235.

Wang, Y., Zhang, X., Jiang, C., Wei, H. \& Wan, J., 2007. Tectonic controls on the late Miocene-Holocene volcanic eruptions of the Tengchong volcanic field along the southeastern margin of the Tibetan plateau, J. Asian Earth Sci., 30(2), 375-389.

Wen, L., Badal, J. \& Hu, J., 2019. Anisotropic $H-\kappa$ stacking and (revisited) crustal structure in the southeastern margin of Tibet, J. Asian Earth Sci., 169, 93-104.

Wessel, P. \& Smith, W.H.F., 1998. New, improved version of generic mapping tools released, EOS, Trans. Am. geophys. Un., 79(47), 579-579.

Wu, T., Zhang, S., Li, M., Qin, W. \& Zhang, C., 2016. Two crustal flowing channels and volcanic magma migration underneath the SE margin of the Tibetan Plateau as revealed by surface wave tomography, J. Asian Earth Sci., 132, 25-39.

$\mathrm{Xu}$, M. et al., 2018. Insight into the subducted Indian slab and origin of the Tengchong volcano in SE Tibet from receiver function analysis, Earth planet. Sci. Lett., 482, 567-579.

Xu, Y.G., Lan, J.B., Yang, Q.J., Huang, X.L. \& Qiu, H.N., 2008. Eocene break-off of the Neo-Tethyan slab as inferred from intraplate-type mafic dykes in the Gaoligong orogenic belt, eastern Tibet, Chem. Geol., 255(34), 439-453.

Yang, H., Hu, J., Hu, Y., Duan, Y. \& Li, G., 2013. Crustal structure in the Tengchong volcanic area and position of the magma chambers, J. Asian Earth Sci., 73, 48-56.
Ye, T., Huang, Q., Chen, X., Zhang, H., Chen, Y.J., Zhao, L. \& Zhang, Y., 2018. Magma chamber and crustal channel flow structures in the Tengchong volcano area from 3-D MT inversion at the intracontinental block boundary southeast of the Tibetan Plateau, J. Geophys. Res. Solid Earth., 123(12), 11 112-11 126.

Yuan, X., Kind, R., Li, X. \& Wang, R., 2006. The S receiver functions: synthetics and data example, Geophys. J. Int., 165(2), 555-564.

Yu, Y., Gao, S.S., Liu, K.H., Yang, T., Xue, M., Le, K.P. \& Gao, J., 2018. Characteristics of the mantle flow system beneath the Indochina peninsula revealed by teleseismic shear wave splitting analysis, Geochem. Geophys. Geosystems., 19(5), 1519-2532.

Zhang, P.Z. et al., 2004. Continuous deformation of the Tibetan Plateau from global positioning system data, Geology, 32(9), 809-812.

Zhang, R., Wu, Y., Gao, Z., Fu, Y. V., Sun, L., Wu, Q. \& Ding, Z., 2017. Upper mantle discontinuity structure beneath eastern and southeastern Tibet: new constraints on the Tengchong intraplate volcano and signatures of detached lithosphere under the western Yangtze Craton, J. geophys. Res., 122(2), 1367-1380.

Zhang, X. \& Wang, Y., 2009. Crustal and upper mantle velocity structure in Yunnan, Southwest China, Tectonophysics, 471(3-4), 171-185.

Zhao, C, Ran, H. \& Chen, K., 2006. Present-day magma chambers in Tengchong volcano area inferred from relative geothermal gradient, Acta Petrol. Sin., 22(6), 1517-1528 (in Chinese with abstract in English).

Zheng, T., Ding, Z., Ning, J., Chang, L., Wang, X., Kong, F., Liu, K.H. \& Gao, S.S., 2018. Crustal azimuthal anisotropy beneath the Southeastern Tibetan Plateau and its geodynamic implications, J. geophys. Res., 123(11), 97339749.

Zhu, L. \& Kanamori, H., 2000. Moho depth variation in southern California from teleseismic receiver functions, J. geophys. Res., 105(B2), 29692980 . 